\title{
Endogenous Local Interaction and Multi-Product Fims
}

Bauke Visser (visser@datacomm.iue.it)

\section{Approved by Giovanni Dosi (dosi@ilasa.ac .at) Leader, TED Project}




\section{Acknowledgements}

I would like to thank Andrzej Baniak, Aedín Doris, Giovanni Dosi, Iouri Kaniovski, Spyros Vassilakis, and Bruno Versaevel for helpful discussions. The usual disclaimer applies. 


\begin{abstract}
Multi-product firms are modeled as endogenously locally interacting entities that gather information on the profitability of product combinations in an environment defined in terms of their currently supplied markets. They learn from their own past play. Local information gathering leads to greater product diversity relative to global gathering. The introduction of more information at the outset and of finer learning mechanisms leads to more instability. Cycles show parts of the economy that are in rest, while others are in a state of flux.
\end{abstract}

Keywords: multi-product firms, information gathering, learning.

JEL classification numbers: C79, D83, L13.

Interim Reports on work of the International Institute for Applied Systems Analysis receive only limited review. Views or opinions expressed herein do not necessarily represent those of the Instiute, its National Memeber Organizations, or other organizations supporting the work. 


\title{
Endogenous Local Interaction and Multi-Product Firms
}

\author{
BaukeVisser(visser@datacomm.iue.it)
}

\section{Introduction}

Formal economic analysis of the multi-product firm tends to be limited to static, full information frameworks in which such a firm is either studied in isolation or in an oligopoly in which all firms offer identical sets of goods. The process of diversification is left undiscussed. Contrary to this static, symmetric, and optimal point of view offered by formal economic theory, dynamics, firm heterogeneity and the need to base decisions on incomplete and distorted information form the main ingredients of the literature on diversification originating in the field of strategic management. Still little is known, however, about the process that leads to the specific direction of diversification, and in particular about the sources of information firms draw on in this process.

In this paper I discuss the effects of two such sources for firm decision making, namely information gathering in the economy and learning from information stored in the firm's memory. A firm combines information on the profitability of certain product combinations it currently observes in the economy with information on the profitability of product sets stored in its memory to decide which products to offer in the next period. I study the effects of different ways of gathering information and different ways of learning about the profitability of product combinations offered in the past. Information can be gathered locally, i.e., in an environment that depends on the markets a firm is currently serving, or globally in the economy as a whole. Information can be learned non-parametrically if the obtained rate of profit is remembered, or parametrically if the parameters underlying the profit rate are stored in memory. The latter is a finer way of learning. As the model of local information gathering used here is an endogenous variant of local interaction models that are currently studied in the literature, the effects of these learning mechanisms are compared to those ensuing from two assumptions concerning the information actors have that are commonly made in models of local interaction. In these models no learning takes place, but either all relevant pay-off information is known from the outset to all players, or players only know their current pay-off and are ignorant as to those of all other actions.

It is shown that local information gathering leads to more diversity in the product sets offered relative to global information gathering. Secondly, the introduction of more information at the outset or of finer learning mechanisms leads to more instability, in the sense that equilibria are reached for less values of the paremeters. Thirdly, in the case of multiple equilibria in the one-shot game, the dynamics of the model show a preference for equilibria showing diversity over ones showing homogeneity in terms of products offered. These equilibria, moreover, tend to maximize the total surplus of the econony. Fourthly, the introduction of local information gathering does not speed up the attainment of equilibrium relative to global information gathering. As this model is an endogenous variant of

Interim Reports on work of the International Institute for Applied Systems Analysis receive only limited review. Views or opinions expressed herein do not necessarily represent those of the Instiute, its National Memeber Organizations, or other organizations supporting the work. 
existing local interaction models, it is interesting to see that the known result of a quicker convergence in case of local interaction does not carry over to the situation analyzed here. Fifthly, the cycles that obtain show that even in a deterministic model firms may react differently to the same environment, and that parts of the economy may be in equilibrium, while others are in a state of flux, merely as a result of differences in information accumulated. Finally, the initial distribution of different product combinations affects the parameter sets for which equilibria obtain for the majority of equilibria; some, however, are attained for parameters that depend on the total number of firms only.

The paper is built up as follows. In section 2 the literature on multi-product firms and diversification is discussed. Section 3 introduces the definitions and assumptions that are applied in section 4 to analyze in depth the co-evolution of a population of multi-product firms. Section 5 concludes.

\section{Multi-Product Firms}

In economics, the theory of multi-product firms is usually conducted within a static, oneshot equilibrium, optimization framework, where a multi-product firm is either studied in isolation, or in an oligopolistic setting where all producers offer the same products, and where no attention is paid to the sources of the information on which decisions are based. These characteristics are clear from the analyses that relate the composition of the range of products offered to economies of scope, the nature of competition, demand interdependencies, and the superiority of an internal capital market over the external one ${ }^{1}$. The symmetry assumption is in general wildly at variance with observed diversification patterns: if one compares firms to patches covering certain parts of the product landscape, then the economy as a whole can be viewed as being made up of partially overlapping patches. The static, one-shot nature impedes the study of the effects of diversification moves. Although observed patterns are explained as the result of optimal decisions, the sources of the information on which these decision are based are not discussed. It is known, however, that diversified companies have difficulties determining the profitability of the products they market. This point is put forward by Kaplan and Johnson, and by Baldwin and Clark who studied the use of capital-budgeting and financial-planning systems; Although these systems were put into place to organise the huge amount of data generated by growing diversification, companies continued to have difficulties obtaining accurate and timely information on total production costs, and on the products that precisely caused these costs ${ }^{2}$. Moreover, since ' $(n)$ ot all the compelling motives for making an investment could be translated into specific revenue and cost projections (...) large strategic investments [like entering a new market, BV] were almost always exempted from the standard review procedures. Such investments did not fit into pre-established categories, did not have fixed time horizons, and often could not satisfy corporate standards for payback or return on investment' (Baldwin and Clark, pp. 83-84 (1994)). Hence, although possibly not based on a leap of faith, major business decisions are not and cannot be based on the rational calculations of economics.

\footnotetext{
${ }^{1}$ For economies of scope, see Baumol, Panzar and Willig (1982); for the nature of competition, see Wolinsky (1986); for demand interdependencies, see Anderson, De Palma and Thisse (1990), and Shaked and Sutton (1990); for the alleged superiority of the internal capital market, see Williamson (1975). For some other reasons, see Jovanovic (1993). For the extension of equilibrium results in oligopolistic situations to multi-product firms, see Okuguchi and Szidarovsky (1990).

${ }^{2}$ See Baldwin and Clark (1994), and Kaplan and Johnson (1987).
}

Interim Reports on work of the International Institute for Applied Systems Analysis receive only limited review. Views or opinions expressed herein do not necessarily represent those of the Instiute, its National Memeber Organizations, or other organizations supporting the work. 
Corporate diversification is also studied in the field of strategic management ${ }^{3}$. Theoretical and empirical work focuses on firms' decisions to diversify, choice of direction of diversification, the choice of the mode of diversification, performance differences associated with different diversity profiles, and the management of diversity ${ }^{4}$. Empirical work is usually based on data on the largest firms in the manufacturing industries of some industrialized country. Although this may imply a considerable bias in the results obtained, as has been pointed out by population ecologists ${ }^{5}$, even on the basis of these studies it is hard to form a judgement on most of the key issues just mentioned. Another weak point is the almost complete neglect of the study of the decision process that leads to the choice of the direction and mode of diversification. In particular, and similar to studies conducted in economics, hardly any attention is paid to the sources of the information required to make such decisions. For example, although many studies have by now established that "firms tend to diversify into industries that are simlar to their primary industry in terms of advertising intensity, R\&D intensity, and/or buyer/seller relationships" or that firms diversify along one of the following dimensions: "technology, products and services, geographic markets, customer segments, and distribution channels" (Ramanujam and Varadarajan (1989), p. 526), it is not clear at all how firms go about collecting information about these dimensions, nor whether the just mentioned dimensions are actually considered when deciding the direction of diversication. It is hard to see why an equal R\&D intensity in, say, the computer industry and the chemical industry would constitute a consideration in the process of deciding in what way to diversify. Nor are such statements very specific or do they have great predictive power. For note that a great many products may be considered similar to, say, a television, depending on the dimension one considers, and even given a particular dimension. Authors taking a resource-based view of the firm relate diversification patterns to the firm's currently unused resources and to the extent to which resources can be deployed to gain or sustain a competitive advantage ${ }^{6}$. These theorists have been criticized for only being able to determine ex-post the value of certain resources ${ }^{7}$. What has apparently not been recognized, however, is that this problem holds a fortiori for the firms under study. How do firms know what their valuable resources are, and how do they know in which markets to operate?

Taking these observations as my point of departure, I study a dynamic model of a population of firms that can offer diverse product combinations, and that explicitly treats the sources of information. The decisions are based on limited, imperfect knowledge as to the profitability of offering these product combinations. The firm's information comes from two sources: rival firms and its memory.

I assume that a firm gathers information on the profitability of the product combinations offered by other firms. I compare the consequences of two ways of gathering information. In the first case, which I call Local Information Gathering (LIG), a firm only observes its rivals, i.e., those firms with which it competes. These are precisely the firms it meets in the market it serves, and with whom, in some sense, a network has been built up. For example, a firm producing good $A$ competes with all those firms that offer at

\footnotetext{
${ }^{3}$ See, e.g., the introduction to Rumelt, Schendel, and Teece (1994).

${ }^{4}$ This classification is taken from Ramanujam and Varadarajan (1989), which constitutes a good overview of the literature until the end of the 1980s.

${ }^{5}$ See Hannan and Freeman (1977), (1989), and Carroll (1985).

${ }^{6}$ For the original statement of the resource-based approach, see Penrose (1959). Some modern contributions are Amit and Schoemaker (1993), Barney (1991), Mahoney and Rajendran Pandian (1992), and Wernerfelt (1984).

${ }^{7}$ See Foss, Knudsen, and Montgomery (1993), and Levinthal (1993).
}

Interim Reports on work of the International Institute for Applied Systems Analysis receive only limited review. Views or opinions expressed herein do not necessarily represent those of the Instiute, its National Memeber Organizations, or other organizations supporting the work. 
least good $A$. If a firm producing, say, good $A$ and $B$ is active as well, this profitability of this product combination is observed by the firm producing just good $A$. In other words, market relations are seen as forming an information network through which factual information on prices, quantities, and profits can be obtained. A firm uses its rivals' current profit rates as guide lines for its own actions. Certain market constellations will be reproduced, while others show ongoing change. The idea that market information on tangible quantities is used as a guide line for a firm's actions, and that this may lead to the reproduction of the market structure can be found as well in a series of papers by Harisson White and Eric Leifer ${ }^{8}$. Limiting information gathering to a firm's rivals will be contrasted with Global Information Gathering (GIG), the situation in which the profitability of all product combinations currently offered by some producer is observed.

The second source of information is information stored in a firm's memory. I assume that a firm stores information on those product combinations it has offered at some stage in the past. Storing information allows a firm to learn, to compare existing situations with past experiences. Suppose again that a firm currently produces good $A$, but that it has produced both $A$ and $B$ in the past. If this firm is to observe some firm producing good $A$ and $B$ and the ensuing profits, it can evaluate this product combination's profitability in the light of its own past experience. I compare two ways of memorizing or learning, parametric and non-parametric learning. In the first case, a firms remembers the parameters underlying the profit it obtained for a certain product combination. In the second case, it simply remembers the level of profit it obtained. Introducing these two ways of learning allows me to study the effect of the level of detail of the learning process on the equilibrium obtained.

In the sequel of the paper I study the effects on the evolution of play and on the equilibria reached of assuming that information is locally or globally gathered, and that learning is parametric or non-parametric. Local information gathering is closely related to local interaction. Since in models of local interaction it is assumed that all relevant information on pay-offs is present from the outset or is never learnt at all, I study the effects of making these assumptions in my model as well. I finally discuss the welfare properties of the equilibria.

\section{Endogenous Interaction and Multi-Product Firms}

Before introducing the required notation, assumptions and definitions I sketch briefly the story that will be formalized. Some terminology that will be defined precisely in the succeeding section is used in an informal way.

In period 0, a population of firms exists in the economy, each of them offering one or more products. All possible product combinations are offered by at least one firm. Each firm obtains a profit level that is determined by the costs of the product set it offers, by the market intercept, and by the number of rivals operating in the markets it serves. Each firm has to decide on next period's production plan: which products will it offer? Since its currently obtained profits are not suggestive as to the profitability of other product combinations, it relies on observations on profit rates obtained by other firms offering different product sets as a guide line for this decision. Such information can be gathered

\footnotetext{
${ }^{8}$ White (1981a), (1981b), (1988), and Leifer (1985). The best starting point is Leifer and White (1987). For a detailed analysis of the relationship between White and Leifer's model and the model to be presented here, see Visser (1996).
}

Interim Reports on work of the International Institute for Applied Systems Analysis receive only limited review. Views or opinions expressed herein do not necessarily represent those of the Instiute, its National Memeber Organizations, or other organizations supporting the work. 
locally or globally. In any case, as each firm updates its production plan, some firms diversify in a seemingly profitable direction, others divest, and some firms may continue last period's operations. Every firm does, however, store information, on the product combination it offered last period in its memory, either by remembering the parameters underlying the profit rate or by memorizing the profit rate it obtained. At the end of the second period, production plans are updated once again. Now, the decision is based on both information gathered in the economy and on information stored in memory. A firm may now react differently to in the economy observed profit signals in the light of past experience. The individual decisions once again lead to certain diversification and divesting patterns. Firms accumulate information through play, and the economy may eventually reach a situation of equilibrium in which every firm repeats what it did in the past and no new information is stored in memory. Or a cycle may be reached, in which certain firms diversify and divest, while others may stick to their knitting. This story is formalized in the following section. The simplest multi-product case, the two goods case, is studied in detail in section 4 .

\subsection{Notation}

The economy consists of consumers and producers. There are $l$ goods, indexed $l=$ $1, \ldots, M$, and $\mathrm{N}$ consumers $i=1, \ldots, N$. Since I want to be able to talk about multiproduct firms I allow firms to produce any combination $\mathcal{P}$ of the $l$ products present in the economy, giving rise to $J=2^{M}-1$ possible product combinations, $\mathcal{P}_{j}, j=1, \ldots, 2^{M}-1$. Representing products by letters $A, B, C, \ldots$, a product combination can be denoted by the letters representing its constituent products, say $\mathcal{P}=A B D$. A firm $i$ produces the quantity $q_{i l}$ of good $l$. A costparameter $F_{\mathcal{P}}$ denotes the cost of producing $\mathcal{P}$. The profit a firm $i$ obtains in period $t$ equals $\Pi^{t}(i)$. Of all the product combinations $\mathcal{P} \in S^{t+1}(i)$ it considers when deciding on next period's product set, a firm $i$ chooses the one that it expects will maximize next period profits, denoted by $\hat{\Pi}^{t+1}(\mathcal{P}, i)$. These expectations are based on information gathered in the economy and on information stored in memory, $\mathcal{M}^{t}(i)$. The specifications of the product sets considered by a producer, $S^{t+1}(i)$, of the expected profits $\hat{\Pi}^{t+1}(\mathcal{P}, i)$, and of the information stored in memory $\mathcal{M}^{t}(i)$, as well as the other assumptions follow in the next subsection. The following list of notation is for the reader's convenience.

$$
\begin{aligned}
\mathcal{P}_{j} & : \text { product set } j \\
\mathcal{P}^{t}(i) & : \text { set of goods firm } i \text { produces at time } t \\
q_{i l} & : \text { the quantity of good } l \text { firm } i \text { manufactures } \\
F_{\mathcal{P}} & : \text { the cost of manufacturing } \mathcal{P} \\
\Pi^{t}(i) & : \text { the level of profits firm } i \text { obtains at time } t \\
\hat{\Pi}^{t+1}(\mathcal{P}, i) & : \text { the expectation held by firm } i \text { at time } t \text { concerning profits } \\
& \text { ensuing from offering } \mathcal{P} \text { at time } t+1 \\
S^{t+1}(i) & : \text { the collection of product sets firm } i \text { considers when deciding on its } \\
& \text { period } t+1 \text { product combination } \\
\mathcal{M}^{t}(i) & : \text { state of memory of firm } i \text { at time } t \\
<\mathcal{M}^{t}(i)>\mathcal{P} & : \text { Indicator function, the value of which is equal to } 1(0) \text { if }
\end{aligned}
$$

Interim Reports on work of the International Institute for Applied Systems Analysis receive only limited review. Views or opinions expressed herein do not necessarily represent those of the Instiute, its National Memeber Organizations, or other organizations supporting the work. 
information on product combination $\mathcal{P}$ is stored (is not stored) in memory of firm $i$ at time $t$

$$
\begin{aligned}
\mathcal{W}^{t}(i) & :\left\{\mathcal{P}<\mathcal{P} \cap \mathcal{P}^{t}(i) \neq \emptyset\right\} \\
N^{t}(\mathcal{P}) & : \text { the number of firms offering product combination } \mathcal{P} \text { at time } t \\
\mathbf{N}^{t} & : \text { the vector }\left(N^{t}\left(\mathcal{P}_{1}\right), \ldots, N^{t}\left(\mathcal{P}_{J}\right)\right)
\end{aligned}
$$

The set $\mathcal{W}^{t}(i)$ is needed when discussing the evolution of play. The definitions of $N^{t}\left(\mathcal{P}_{j}\right)$ and $\mathbf{N}^{t}$ are for book-keeping purposes.

\subsection{Definitions and Assumptions}

In this section I give the formal definitions of local and global information gathering, of parametric and non-parametric learning, and of the collection of product combinations from which a firm picks its next period product set. The choice of the next period product set is described in detail. The assumptions concerning the initial state are given, as well as the ones limiting the dynamics of play.

The initial state at time $t=0$ is fully characterized by

$$
\left\{i, \mathcal{P}^{0}(i),\left\{q_{i l}\right\}_{l}, \mathcal{M}^{0}(i)\right\}_{i=1, \ldots, N}
$$

i.e., by the set of firms, the products they offer, the quantities they offer, and the state of their memories. Since there are $l$ goods in the economy, there are $J=2^{M}-1$ possible product combinations. I assume that

Assumption 1 At time $t=0$ all $J$ product combinations are being produced by at least one firm.

This implies that $\mathbf{N}^{0}>\mathbf{0}$. This assumption is made to prohibit the possible differential capacities of firms to introduce new products from affecting the results. I assume as well that $^{9}$

\section{Assumption 2}

$$
q_{i l}= \begin{cases}1 & \text { if } l \in \mathcal{P}(i) \\ 0 & \text { otherwise }\end{cases}
$$

In words, if a producer operates in a certain market it produces exactly one unit of the product. This amounts to assuming that a producer is present or not in a market, which is all that matters to obtain information on firms operating in that market. Whatever the type of information stored in memory (information on cost parameters, on market intercepts, on total profits obtained) the following assumption applies.

Assumption 3 The only information a firm $i$ at time $t$ has stored in its memory $\mathcal{M}^{t}(i)$ is information on all those product combinations it has offered in the past. If information on product combination $\mathcal{P}$ is present (is not present) at time $t$ in $i$ 's memory then this will be denoted by $<\mathcal{M}^{t}(i)>_{\mathcal{P}}=1(0)$. As a matter of convention, if a firm offers product combination $\mathcal{P}$ for the first time at time $t$, information on this product set is stored at the same moment in his memory, i.e. $\left\langle\mathcal{M}^{t}(i)>_{\mathcal{P}}=1\right.$.

\footnotetext{
${ }^{9}$ Making $q_{i l}$ independent of cost parameters leaves out many interesting oligopolistic interactions on the quantity level. The consequences of introducing such a dependence are discussed in Appendix A.

Interim Reports on work of the International Institute for Applied Systems Analysis receive only limited review. Views or opinions expressed herein do not necessarily represent those of the Instiute, its National Memeber Organizations, or other organizations supporting the work.
} 
Consequently, the only information stored in memory in period 0 is information on the product combination offered in that period.

The profit a firm obtains in a given period is determined by the cost of producing the product set, the market demand functions, and the number of firms operating in the market it serves. I assume that the total cost of producing $\mathcal{P}$ equals $F_{\mathcal{P}}$.

This captures the above mentioned observation that multi-product firms face difficulties determining in an accurate way the costs of individual products they are manufacturing. In order to keep analysis tractable inverse aggregate demand funtions for every good $l$ is linear:

$$
P_{l}\left(Q_{l}\right)=D_{l}-Q_{l}, \quad l=1, \ldots, M
$$

where $D_{l}$ is the market-intercept for good $l$, and $Q_{l}$ equals the total quantity offered in this market. This means that demand for a product is independent of the demand for any other good. Profits for a firm $i$ are then equal to

$$
\Pi^{t}(i)=\sum_{l \in \mathcal{P}^{t}(i)}\left(D_{l}-\sum_{\left\{\mathcal{P}_{j} \mid l \in \mathcal{P}_{j}\right\}} N^{t}\left(\mathcal{P}_{j}\right)\right)-F_{\mathcal{P}^{t}(i)}
$$

An example may help to illustrate.

Example Suppose $N^{t}(A)>0, N^{t}(B)=0, N^{t}(A B)>0$. Suppose that firm $i$ offers only good $A$ at time $t$. Its profits then equal

$$
\begin{gathered}
\Pi^{t}(i)=\sum_{l \in A}\left(D_{l}-\sum_{\left\{\mathcal{P}_{j} \mid l \in \mathcal{P}_{j}\right\}} N^{t}\left(\mathcal{P}_{j}\right)\right)-F_{A}= \\
\left(D_{A}-\sum_{\left\{\mathcal{P}_{j} \mid A \in \mathcal{P}_{j}\right\}} N^{t}\left(\mathcal{P}_{j}\right)\right)-F_{A}= \\
D_{A}-\left(N^{t}(A)+N^{t}(A B)\right)-F_{A}
\end{gathered}
$$

The dynamics of play is determined by the information firms have. On the basis of this information a firm chooses the product combination it believes will maximize its next period profits.

A firm $i$ at time $t$ obtains information about the profitability of product combinations different from the one it is currently offering from two distinct sources. First of all it contemplates information on profit stored in memory $\mathcal{M}^{t}(i)$. This reflects information the firm has accumulated by its own past play. I assume that this information can be stored in two different ways, either parametrically or non-parametrically.

Definition 1 A firm $i$ is said to store its information parametrically, or to learn parametrically if it remembers the parameters (the intercepts of the inverse demand curves of the markets, and the costparameter) underlying the profit it obtained.

Example Suppose firm $i$ 's memory contains information on good $A$, and on $\operatorname{good} B$, but not on the combination of good $A$ and $B$. In case of parametric learning this amounts to firm $i$ having the intercept and the cost parameter for both good $A$ and good $B$ in its memory. That is, firm $i$ knows $D_{A}$ and $F_{A}$, and $D_{B}$ and $F_{B}$. It does not know the cost parameter $F_{A B}$.

Interim Reports on work of the International Institute for Applied Systems Analysis receive only limited review. Views or opinions expressed herein do not necessarily represent those of the Instiute, its National Memeber Organizations, or other organizations supporting the work. 
Parametric learning can be regarded as an extreme case of learning, in that it presupposes a firm to know the functional form underlying the profit function, and to be endowed with the capacity to disentangle the contributions to obtained profits of market intercepts, cost parameter, and the numbers of firms operating in its markets. It is therefore interesting to see what happens in the opposite case where a firm only remembers the level of profit it obtained:

Definition $2 A$ firm $i$ is said to store its information non-parametrically, or to learn non-parametrically if it remembers the profits it obtained the last time it offered a particular product combination. As a matter of convention, the profit a firm currently obtains for offering product set $\mathcal{P}$ is the value stored in memory for this product combination.

Example Suppose again that firm $i$ 's memory contains information on $A$, and on good $B$. Since good $A$ is the good currently offered, the information on $A$ stored in memory in case of non-parametric learning equals its currently obtained level of profit $\Pi^{t}(i)$. Since $<\mathcal{M}^{t}(i)>_{\{B\}}=1$ the information stored on $B$ equals the most recently obtained level of profit on $B$, say $\Pi^{\tau}(i)$, where $\tau<t$ is the most recent period in which $i$ offered good $B$.

The second source of information is the result of information gathering, and here the definitions of local and global information gathering are crucial.

Definition 3 Information is said to be gathered locally if the product sets on which information is gathered are overlapping with the one currently offered by a firm. That is, information gathering by firm $i$ is limited to the set of product combinations $\left\{\mathcal{P} \mid \exists n^{\prime} \in\right.$ $\left.\{1, \ldots, N\}: \mathcal{P}=\mathcal{P}^{t}\left(n^{\prime}\right) \wedge \mathcal{P} \cap \mathcal{P}^{t}(i) \neq \emptyset\right\}$

where ' $\wedge$ ' stands for the logical operator 'and'. This definition of local information gathering makes the current model similar to existing models of local interaction. The main difference is the endogeneity of local information gathering as defined here as opposed to the exogeneity of local interaction in the literature. The existing models of local interaction of which I am aware postulate a fixed spatial distribution of agents that interact with their neighbours only. Although the actions these neighbours take may vary, the identity of an agent's neighbours stays the same ${ }^{10}$. Here, however, the product combination a firm offers, i.e., a choice variable, determines the identity of the firms it meets.

The effects of local information gathering on the evolution of play of the population of firms will be compared to those of global information gathering.

Definition 4 Information is said to be gathered globally if the product sets on which information is gathered include all product sets currently present in the economy: $\left\{\mathcal{P} \mid \exists n^{\prime} \in\right.$ $\left.\{1, \ldots, N\}: \mathcal{P}=\mathcal{P}^{t}\left(n^{\prime}\right)\right\}$

In case of local information gathering I will moreover assume that a firm does not close down all its operations, starting from scratch with a new set of products. This limits the range of changes in the products offered by a firm in any two successive periods.

Assumption 4 In case of local information gathering the set of product combinations a firm $i$ that currently produces $\mathcal{P}^{t}(i)$ can offer in period $t+1$ is a subset of $\mathcal{W}^{t}(i):=\{\mathcal{P}<$ $\left.\mathcal{P} \cap \mathcal{P}^{t}(i) \neq \emptyset\right\}$

\footnotetext{
${ }^{10}$ See, for example, Blume (1993), Ellison and Fudenberg (1993), and An and Kiefer (1995).
} 
Such a limitation in the range of possible successive product combinations is not applied to global information gathering. Note that in either case information gathering is limited to those product combinations that are currently being manufactured in the economy.

An important assumption limiting the possible dynamics is that

Assumption 5 A firm $i$ is not allowed to collapse two or more product sets into one product set.

This means that a firm who does not observe the product set $\{A, B\}$ in the economy, and who does not have information stored in memory on this product combination is not allowed to say, well, I am now producing $A$, I offered only good $B$ at some stage in the past, let me now combine these two products and offer in the next period both $A$ and $B$.

I can now specify the collection of product sets out of which a firm $i$ chooses the product combination for period $t+1$. I call this collection the firm's action set $S^{t+1}(i)$. Combining the information stored in memory with the information gathered in the economy one obtains the set of product combinations a firm considers at time $t$ :

Definition 5 In case of local information gathering the set of product combinations (action set) a firm $i$ with memory $\mathcal{M}^{t}(i)$ can offer at time $t+1$, given that the other firms in the economy offer $\left\{\mathcal{P}^{t}\left(n^{\prime}\right)\right\}_{n^{\prime}}$ equals

$$
\begin{aligned}
S_{l}^{t+1}(i):= & \left\{\mathcal{P} \mid \exists n^{\prime} \in\{1, \ldots, N\}: \mathcal{P}=\mathcal{P}^{t}\left(n^{\prime}\right) \wedge \mathcal{P} \cap \mathcal{P}^{t}(i) \neq \emptyset\right\} \\
& \cup\left\{\mathcal{P} \mid<\mathcal{M}^{t}(i)>_{\mathcal{P}}=1 \wedge \mathcal{P} \cap \mathcal{P}^{t}(i) \neq \emptyset\right\}
\end{aligned}
$$

Definition 6 In case of global information gathering the set of product combinations (action set) a firm $i$ with memory $\mathcal{M}^{t}(i)$ can offer at time $t+1$, given that the other firms in the economy offer $\left\{\mathcal{P}^{t}\left(n^{\prime}\right)\right\}_{n^{\prime}}$ equals

$$
S_{g}^{t+1}(i):=\left\{\mathcal{P} \mid \exists n^{\prime} \in\{1, \ldots, N\}: \mathcal{P}=\mathcal{P}^{t}\left(n^{\prime}\right)\right\} \cup\left\{\mathcal{P} \mid<\mathcal{M}^{t}(i)>_{\mathcal{P}}=1\right\}
$$

Example Suppose there are $M=2$ goods in the economy, $A$ and $B$. Then, excluding the empty set, there are 3 possible product sets:

$$
\{A\},\{B\},\{A, B\}
$$

Suppose that at time $t$, a firm $i$ offers good $A$, that there are in total $N^{t}(A)>0$ firms producing good $A$, no firms offering good $B$ (hence, $N^{t}(B)=0$ ), and some firms offering both good $A$ and $B$, or $N^{t}(A B)>0$. Suppose moreover that this firm $i$ has accumulated information on product sets $A$, and on $B$. That is, $<\mathcal{M}^{t}(i)>_{\{A\}}=<$ $\mathcal{M}^{t}(i)>_{\{B\}}=1$. Hence this firm's action set in case of local information gathering amounts to

$$
S_{l}^{t+1}(i)=\{\{A\},\{A, B\}\} \cup\{\{A\}\}=\{\{A\},\{A, B\}\}
$$

while in the case of global information gathering the action set becomes

$$
S_{g}^{t+1}(i)=\{\{A\},\{A, B\}\} \cup\{\{B\}\}=\{\{A\},\{B\},\{A, B\}\}
$$

Interim Reports on work of the International Institute for Applied Systems Analysis receive only limited review. Views or opinions expressed herein do not necessarily represent those of the Instiute, its National Memeber Organizations, or other organizations supporting the work. 
The decision to produce a particular product combination in period $t+1$ depends on the firm $i$ 's perception at time $t$ of the profitability of the various product combinations that are in its action set. A firm chooses the product combination $\mathcal{P} \in S^{t+1}(i)$ that it believes will maximize its next period profits $\hat{\Pi}^{t+1}(\mathcal{P}, n)$. These beliefs are affected by the type of information on previously offered product sets stored in memory.

For the case of non-parametric learning, this information is directly comparable to the profit levels observed in the economy. In case of parametric learning an additional assumption is required to transform the knowledge stored in memory into an expected level of profit: the values of parameters stored in memory have to be combined with numbers of firms offering relevant product combinations to make the calculation of a profit level possible. The following assumption has this effect.

Assumption 6 When deciding which product combination to offer in the next period, a firm conjectures that the other firms continue with their currently offered product combinations.

Before describing precisely in what way expected profits are determined, I make a final assumption.

Assumption 7 The dynamics of the model is deterministic. That is, the choice of a product set is not subject to randomness.

This implies that firms that start out with the same product set behave symmetrically: they gather the same information, take identical decisions, obtain the same profits, and store the same information in their memories. This assumption is made for convenience.

Consequently, the levels of expected profit on which firm $i$ bases its decisions are the following. Firstly, the profit firm $i$ expects to make in the succeeding period with its current product set $\mathcal{P}$ equals its currently obtained profit

$$
\hat{\Pi}^{t+1}(\mathcal{P}, i)=\Pi^{t}(i) \text { if } \mathcal{P}=\mathcal{P}^{t}(i)
$$

irrespective of whether information is stored parametrically or non-parametrically. Secondly, in case of both parametric and non-parametric learning, a firm $i$ that observes a specific product combination $\mathcal{P}$ and the profit ensuing from offering this product set, takes this level of profit as given, if it has not offered this product set itself at some point in the past:

$$
\hat{\Pi}^{t+1}(\mathcal{P}, i)=\Pi^{t}\left(n^{\prime}\right) \text { if }<\mathcal{M}_{t}(i)>_{\mathcal{P}}=0
$$

If, on the other hand, $i$ has offered the product set $\mathcal{P}$ at some time $\tau<t$ itself, and hence $<\mathcal{M}^{t}(i)>_{\mathcal{P}}=1$, then it uses the information stored in memory to reconsider $\mathcal{P}$ 's profit rate. In case of non-parametric learning it simply replaces the currently observed profit rate, with the one it obtained itself most recently:

$$
\hat{\Pi}^{t+1}(\mathcal{P}, i)=\Pi^{\tau}(i) \text { if }<\mathcal{M}^{t}(i)>_{\mathcal{P}}=1
$$

where $\tau<t$ is the most recent period in which $i$ offered $\mathcal{P}$. In case of parametric learning, the firm combines information stored in memory with the conjecture that all other firms continue with their current product combinations to determine what the effect will be of its move into a certain product combination. Formally, this amounts to

$$
\hat{\Pi}^{t+1}(\mathcal{P}, i)=\sum_{l \in \mathcal{P}}\left(D_{l}-\sum_{\left\{\mathcal{P}^{\prime} \mid l \in \mathcal{P}^{\prime}\right\}}\left[N^{t}\left(\mathcal{P}^{\prime}\right)+I\left(\mathcal{P}^{\prime}, \mathcal{P}, n, t\right)\right]\right)-F_{\mathcal{P}}
$$

Interim Reports on work of the International Institute for Applied Systems Analysis receive only limited review. Views or opinions expressed herein do not necessarily represent those of the Instiute, its National Memeber Organizations, or other organizations supporting the work. 
where

$$
I\left(\mathcal{P}^{\prime}, \mathcal{P}, n, t\right)= \begin{cases}1 & \text { if } \mathcal{P}^{\prime}=\mathcal{P} \\ -1 & \text { if } \mathcal{P}^{\prime}=\mathcal{P}^{t}(i) \\ 0 & \text { otherwise }\end{cases}
$$

The term $I(\cdot)$ captures the possible effects on profits of movements into and out of a particular product combination. If a firm $i$ is indifferent between its current product set and some other product set $\mathcal{P} \in S^{t+1}(i)$. An equilibrium is reached when both the product set and the information stored in memory of every firm does not change with time. Note especially the requirement on the information stored in memory. It is conceivable that all firms at some moment $t_{2}$ are producing what they produced at some moment $t_{1}$ in the past. If, however, the information on various product combinations stored in memory has changed in the mean time, they may very well react differently to the same observed profitability of product sets. An equilibrium or a cycle has then not yet been reached.

In summary, the evolution of play is fully characterized as follows:

\section{Evolution of Play}

initial state

$$
\begin{gathered}
\mathcal{P}^{0}(i) \in\left\{\mathcal{P}_{j}\right\}_{j}, \quad \text { for all } n \\
<\mathcal{M}^{0}(i)>_{\mathcal{P}}= \begin{cases}1 & \text { if } \mathcal{P}=\mathcal{P}^{0}(i) \\
0 & \text { otherwise }\end{cases} \\
N^{0}\left(\mathcal{P}_{j}\right)>0, \quad j=1, \ldots, J
\end{gathered}
$$

dynamics

$$
\begin{aligned}
& \mathcal{P}^{t+1}(i)=\arg \max \hat{\Pi}^{t+1}\left(\mathcal{P}_{j}, i\right), \quad \mathcal{P}_{j} \in S^{t+1}(i) \\
& <\mathcal{M}^{t+1}(i)>_{\mathcal{P}}= \begin{cases}1 & \text { if } \mathcal{P}=\mathcal{P}^{t+1}(i) \\
<\mathcal{M}^{t}(i)>_{\mathcal{P}} & \text { otherwise }\end{cases} \\
& N^{t+1}\left(\mathcal{P}_{j}\right)=\sum_{i} I\left(\mathcal{P}^{t+1}(i), \mathcal{P}_{j}\right)
\end{aligned}
$$

where $I\left(\mathcal{P}^{t+1}(i), \mathcal{P}_{j}\right)$ is equal to 1 if $\mathcal{P}^{t+1}(i)=\mathcal{P}_{j}$, and is equal to 0 otherwise.

possible equilibria and cycles

$$
\begin{gathered}
\mathcal{P}^{t+\theta}(i)=\mathcal{P}^{t}(i), \text { for all } n \\
<\mathcal{M}^{t+\theta}(i)>_{\mathcal{P}}=<\mathcal{M}^{t}(i)>_{\mathcal{P}}, \text { for all } n, \text { and all } \mathcal{P} \\
N^{t+\theta}\left(\mathcal{P}_{j}\right)=N^{t}\left(\mathcal{P}_{j}\right)
\end{gathered}
$$

where $\theta$ is an integer, and should take on the same value throughout the statement of the termination of the evolution of play. If $\theta=1$, an equilibrium has been reached, while if $\theta>1$ a cycle has started. 


\section{The Two Goods Case}

In this section I study in depth the evolution of play in the case where there are just 2 goods, $A$ and $B$, in the economy. Let $\mathbf{N}^{0}=\left(N^{0}(A), N^{0}(B), N^{0}(A B)>0\right.$ be the initial distribution of product sets, where I will write $\left(N^{0}(A), N^{0}(B), N^{0}(A B)\right)=\left(N_{A}, N_{B}, N_{A B}\right)$. The effects of the four different combinations of information gathering and learning are discussed, and compared to one-shot games, in terms of the types of equilibria and cycles reached, the time required to converge, and the welfare properties.

Since profits are determined by the product combination offered, $\Pi_{A}, \Pi_{B}$, and $\Pi_{A B}$ denote the profit obtained when offering good $A$, good $B$, and goods $A$ and $B$, respectively. Time superscripts are suppressed as this does not cause any confusion. Profit comparisons are based on expressions of the type $\Pi_{A}(\mathbf{N})-\Pi_{A B}(\mathbf{M})$, where $\mathbf{N}$ and $\mathbf{M}$ represent two (identical or different) distributions of product combinations. When making such comparisons one can exploit the fact that the total number of firms is fixed. Hence ${ }^{11}$,

$$
\begin{aligned}
\Pi_{A}(\mathbf{N})-\Pi_{B}(\mathbf{M}) & =\alpha-\beta+N(B)-M(A) \\
\Pi_{A B}(\mathbf{N})-\Pi_{A}(\mathbf{M}) & =\beta-N(A B)-M(B) \\
\Pi_{A B}(\mathbf{N})-\Pi_{B}(\mathbf{M}) & =\alpha-N(A B)-M(A)
\end{aligned}
$$

where $^{12}$

$$
\alpha:=D_{A}+\left(F_{B}-F_{A B}\right) \text { and } \beta:=D_{B}+\left(F_{A}-F_{A B}\right)
$$

Since the values of these parameters determine for a particular initial distribution of product combinations and for a particular value of $i$ the evolution of play, their interpretation is important. The parameter $\alpha$ which appears when comparing profits of producing only $B$ to profits of manufacturing both $A$ and $B$ equals the sum of the $D_{A}$ and $\left(F_{B}-F_{A B}\right)$. $D_{A}$ is the market intercept of the market that is served by a firm supplying both $A$ and $B$, but that is not served by a firm making only $B$. The higher its value, the more profitable producing both instead of just $B$. The more costly producing both $A$ and $B$ relative to producing good $B$ only, the lower the value of $\left(F_{B}-F_{A B}\right)$. Hence, $\alpha$ captures the relative profitability of $A B$ over $B$ abstracting from the actual number of firms offering certain product combinations. The same holds, mutatis mutandis for $\beta$.

Before turning to the dynamics, I show the equilibria of the one-shot game. Here I have to discuss two aspects, the first being the set of actions relative to which equilibria are defined, and the second being the set of relevant equilibria.

The equilibria of the one-shot, complete information game will be used as a benchmark to study the effects of learning and type of information gathering. Remember that in the dynamic games all product sets are assumed present from the outset, and that $\left(N_{A}, N_{B}, N_{A B}\right)$ is the initial distribution of product sets. Given the deterministic dynamics of the model the only equilibria one can possibly observe are equilibria in which all $N_{A}$ producers initially producing good $A$ end up producing, say, both good $A$ and $B$. Moreover, as will be shown shortly, the set of equilibria that is reached in any of the dynamic games is even more limited. Attention in the one-shot game will therefore be limited to the equilibria reached in at least one of the dynamic games. These equilibria are called the relevant equilibria.

\footnotetext{
${ }^{11}$ It is not convenient to rewrite $N(A B)=N-N(A)-N(B)$ as this makes the interpretation of $\alpha$ and $\beta$ cumbersome.

${ }^{12}$ Sufficient conditions for negative values of $\alpha$ and $\beta$ to be feasible with positive profits are $2 N-D_{B}<0$ and $2 N-D_{A}<0$.
}

Interim Reports on work of the International Institute for Applied Systems Analysis receive only limited review. Views or opinions expressed herein do not necessarily represent those of the Instiute, its National Memeber Organizations, or other organizations supporting the work. 
What constitutes an equilibrium depends on the action spaces agents have. The correct comparison between the one-shot game and the dynamic games in case of GIG is made when the equilibria of the former are defined relative to an action space that includes all product sets:

$$
A(i)=\{\{A\},\{B\},\{A, B\}\}
$$

irrespective of $i$. Such an action set will be called a GIG action set. With LIG, on the other hand, equilibrium strategies in the one-shot game are those strategies that maximize profit from among the set of overlapping product combinations:

$$
\begin{gathered}
A(i)=\{\{A\},\{A, B\}\} \text { if } \mathcal{P}(i)=A \\
A(i)=\{\{B\},\{A, B\}\} \text { if } \mathcal{P}(i)=B \\
A(i)=\{\{A\},\{B\},\{A, B\}\} \text { if } \mathcal{P}(i)=A B
\end{gathered}
$$

Such action sets are called LIG action sets. In summary, the benchmark model is the game defined by

$$
\Gamma=\{n, A(i), \Pi(i)\}_{n=1, \ldots, N}
$$

where the first element denotes the firms, $A(i)$ the action sets, and $\Pi(i)$ the profit functions.

Figure 1 and 2 show the relevant equilibria of the one-shot, complete information game with GIG- and LIG-action sets, respectively ${ }^{13}$. The equilibria that obtain are written within the area for which they hold, or arrows point inside the area for which they hold. In figure 2 , in case of the equilibria $(0, N, 0),(0,0, N),\left(N_{A}, N_{B}+N_{A B}, 0\right)$, and $\left(N_{A}+N_{A B}, N_{B}, 0\right)$ arrows point to the lines determining the region for which these equilibria obtain. For the areas where no equilibrium obtains, the system cycles between two states. Such situations are therefore called cycles.

The first of the two major differences between these two figures are the parameter values for which distinct groups of firms produce different goods. In case of LIG-action sets, the set of parameter values for which firms producing different goods co-exist is clearly larger. This holds because the set of out-of-equilibrium actions is larger in case of global information gathering than in case of local information gathering. Consequently, less restrictions are being imposed in the latter case. The second major difference is the presence of multiple equilibria in figure 2 , and their absence in figure 1 . Hence, although the set of parameter values for which distinct firms produce distinct goods is larger, it is not clear what equilibrium will actually be selected. There is hence a clear interest in knowing which equilibrium will be selected under different specifications of storing information.

\subsection{Summary Observations}

Figures 3 and 4 show the equilibria that obtain in case of parametric learning with GIG and LIG, respectively. The pair of figures 5 and 6 show the equilibria that obtain in case of non-parametric learning in case of GIG and LIG, respectively. The following statements summarize the main observations on the different regimes studied here:

- Local information gathering leads to greater diversity of the products being offered than global information gathering, irrespective of the type of learning. Making information gathering local instead of global leads to larger parameter sets for which

\footnotetext{
${ }^{13}$ Appendix B states the propositions on which these figures are based.
}

Interim Reports on work of the International Institute for Applied Systems Analysis receive only limited review. Views or opinions expressed herein do not necessarily represent those of the Instiute, its National Memeber Organizations, or other organizations supporting the work. 
different firms offer non-overlapping product sets. In case of GIG such equilibrium constellations are either limited to small regions of the parameter space, or are lacking completely. In the latter case, they are either replaced by cycles, or by equilibria in which all firms offer the same product combinations. The reason is that initially diversity is at its maximum as all product sets are being offered in the economy. Movements away from this situation are more limited in case of local information gathering than in case of global information gathering.

- Non-parametric learning leads to equilibria for more parameter values $(\alpha, \beta)$ than does parametric learning, irrespective of the type of information gathering. Indeed, in case of non-parametric learning cum LIG, the distributions $\left(0, N_{B}+N_{A B}, N_{A}\right)$ and $\left(N_{A}+N_{A B}, 0, N_{B}\right)$ are reached. These are not attained in any other dynamic situation. The intuition behing this result is that more detailed information is used in determining the future product sets in case of parametric learning than in case of non-parametric learning. Consequently, less parameter combinations will satisfy the stricter requirements.

- In the one-shot complete information game with LIG-action sets multiple equilibria obtain. It is standard to rank the equilibria and to see whether the equilibrium that is better in some sense is reached. Such a criterion, like Pareto dominance or risk dominance, is based on a comparison of the pay-offs under different strategy combinations of the one-shot game. The welfare measure that readily suggests itself here is the total surplus, i.e., the sum of consumer surplus and profits. Note that when multiple equilibria may obtain, one and the same equilibrium is not necessarily the best throughout the whole set. In the dynamic games, irrespective of the type of learning, equilibria showing diversity instead of homogeneity in terms of products offered are selected. These equilibria maximize the total surplus for the larger part of the parameter values. For some values, however, the second best obtains ${ }^{14}$.

- Ellison (1993) showed that the introduction of local interaction in Kandori, Mailath and Rob's (1993) global random matching model reduced the expected waiting time to reach the risk-dominant equilibrium. The introduction of local information gathering in my model does not necessarily speed up the time it takes to reach an equilibrium, relative to global information gathering. Local information gathering takes more time to bring the system to equilibrium every time an equilibrium is involved in which no producer offers product combination $A B$. This result is independent of the number of firms in the economy. The explanation is that the product set $A B$ is 'connected' with every other product set present in the economy in case of LIG, and, more to the point, that makes that in principle any product set is connected to every other in at most one step. The analysis suggests that with the introduction of more goods, the differences between LIG and GIG in terms of time spells needed to reach an equilibrium will become more pronounced as this inevitably leads to an increase in the upperbound of the required number of steps to go from one product set to another.

My conjecture is that if the equilibrium product combination is overlapping with the initially offered product set convergence will be faster under LIG than under GIG, since the number of possible product combinations that are taken into account in

\footnotetext{
${ }^{14}$ For details, see Appendix C.
}

Interim Reports on work of the International Institute for Applied Systems Analysis receive only limited review. Views or opinions expressed herein do not necessarily represent those of the Instiute, its National Memeber Organizations, or other organizations supporting the work. 
the latter case is at least as big as in the former. Hence, the probability that a firm chooses a non-equilbrium product combination is higher, ceteris paribus, under GIG than under LIG. If, on the other hand, the initial product set and the equilibrium product combination do not overlap, GIG is likely to lead the system faster to equilibrium than LIG, for GIG does not ignore such product combinations.

- Two types of cycles are obtained, whatever the type of information gathering or learning. The first type, a generic example being $(0, N, 0) \longleftrightarrow\left(0, N_{B}, N_{A}+N_{A B}\right)$, is a situation in which different firms react differently to the same environment. Interestingly, this shows that a stochastic element is not required to generate different reactions to the same environment: all it takes is a difference in information accumulated in the course of play, as caused by differences in product combinations offered.

The second case, say, $\left(N_{A}, N_{B}, N_{A B}\right) \longleftrightarrow\left(N_{A}, 0, N_{B}+N_{A B}\right)$, shows that the economy can consist of parts that are in equilibrium, while in other parts changes are still going on. This holds for both the producer's and the consumer's side. For note that the number of producers supplying either good B or both good A and B changes every period, while the number of suppliers of just good A stays fixed. From the consumers' point of view, this implies a constant supply of good B and a periodically changing supply of good A.

- Whatever the type of information gathering and learning the parameter sets for which most equilibria are reached depend on the initial distribution of firms over product sets. Some equilibria, however, are reached for parameter values that depend on the total number of firms only. The latter holds for $(N, 0,0)$, and $(0, N, 0)$ in case of GIG and parametric learning, and for $(0,0, N)$ in case of parametric learning and any type of information gathering.

As noted in section 3.2, the literature on local interaction limits attention to two opposite assumptions concerning the information on which actors base their decisions: either an actor has only information on the pay-off of its current action, or all pay-off relevant information is present from the outset. In either case, no learning takes place in the course of play. Figures 7 and 8 show the equilibria when nothing is known at the outset and nothing is learned either. As no information gathering takes place the difference between these two figures follows from the fact that the equilibria in the second case are the result of a dynamics where successive states are required to be overlapping. Such a condition is not imposed on the dynamics giving rise to the equilibria in the first case. Specifying the dynamics in this way enhances comparability of these figures with figures 3 to 6 .

In figures 9 and 10 the equilibria are shown when all parameter values are known from the beginning of play. The restriction on successive product combinations just mentioned holds as well for the dynamics underlying figure 10 .

- Under the assumption that firms have no knowledge of product combinations different from the one they are currently offering equilibria obtain for every value of $(\alpha, \beta)$ under both GIG and LIG. In case of GIG only those equilibria are reached in which all firms offer the same product set, while LIG gives rise to equilibria showing the co-existence of firms offering non-overlapping product sets.

Interim Reports on work of the International Institute for Applied Systems Analysis receive only limited review. Views or opinions expressed herein do not necessarily represent those of the Instiute, its National Memeber Organizations, or other organizations supporting the work. 
- Comparing the effects of the assumption that firms only have knowledge of their present product sets to the effects of assuming that firms know all relevant payoff information from the outset, one observes that the range of values of $(\alpha, \beta)$ for which equilibria are obtained shrinks. This is a consequence of the fact that assuming more information from the outset implies more restrictions that should be satisfied in equilibrium. The diversity of product sets offered in equilibrium increases under either type of information gathering. LIG leads to a greater diversity of possible equilibria as compared to GIG.

- The overall effect of introducing more information, or finer learning mechanisms is the attainment of equilibria for more restricted sets of the parameter space. This is clear from comparing the sequence of figures representing the equilibria attained when from the outset firms only have information on the current product combination (figure 7 or figure 8 ), when at the beginning firms only have information on the current product combination and learning is non-parametric (figure 3 or figure 4), when at the beginning firms only have information on the current product combination and learning is parametric (figure 5 or figure 6 ), and when firms have all relevant information from the very beginning (figure 9 or figure 10). This holds whether information is gathered locally or globally.

\section{Conclusion}

This paper discussed the evolution of a population of multi-product firms that base their diversification and divesting decisions on the information gathered in the economy and on information stored in memory. The diversity of the product sets offered in equilibrium and the parameter values for which these equilibrium obtain are determined by the interplay of two factors: the type of information gathering, and the level of detail of the learning process. Local information gathering, i.e., information gathering that is limited to a neighbourhood of the currently offered product set leads to more diversity then does global information gathering. Starting in a situation where all possible product combinations are present an information gathering process which is defined relative to the presently offered product set limits the range of possible future product sets more than economy wide information gathering.

Finer learning mechanisms lead to equilibrium for more restricted sets of parameters, as more restrictions should be satisfied in equilibrium. In this sense, the introduction of finer learning mechanisms or more information from the very beginning leads to more instability. Cycles show parts of the economy being in rest, while others remain in a state of flux.

From a methodological point of view, the paper shows how information gathering can be endogenized and how individual learning can be introduced in a model of local interaction.

This paper points towards an important question of empirical nature: what kind of information gathering structures have firms put into a place, and what form does organizational learning take on? Research along these lines is still in its infancies ${ }^{15}$, but is of great importance as an empirical test of the model proposed here.

\footnotetext{
${ }^{15}$ Two interesting references are DiBella, Nevis, and Gould (1996) and Miller (1963).
} 


\section{Appendix}

\section{A Making $q_{i l}$ dependent on cost-parameters}

In this section I will give some indications as to the problems one encounters if the quantity decision $q_{i l}$ is made dependent on cost parameters.

For the sake of convenience I assume that all firms offering the same product combinations face the same cost-parameters, and behave equally in all respects. For the two goods case, let $\left(c_{j}, F_{j}\right)$ denote the marginal cost and the fixed cost, respectively of producing product combination $j=A, B, A B$. Let $q_{A}\left(q_{B}\right)$ denote the quantity produced of good $A(B)$ for the one-product firms, while $q_{A 3}\left(q_{B 3}\right)$ denote the quantity of good $A(B)$ a firm offering both goods supplies.

Since

$$
\begin{gathered}
\Pi_{A}(\mathbf{N})=\left(D_{A}-N(A) q_{A}-N(A B) q_{A 3}-c_{A}\right) q_{A}-F_{A} \\
\Pi_{B}(\mathbf{N})=\left(D_{B}-N(B) q_{B}-N(A B) q_{B 3}-c_{B}\right) q_{B}-F_{B}, \text { and } \\
\Pi_{A B}(\mathbf{N})=\left(D_{A}-N(A) q_{A}-N(A B) q_{A 3}-c_{A B}\right) q_{A 3}+ \\
\left(D_{B}-N(B) q_{B}-N(A B) q_{B 3}-c_{A B}\right) q_{B 3}-F_{A B}
\end{gathered}
$$

the optimal quantities supplied equal

$$
\begin{gathered}
q_{j}^{*}=\frac{D_{j}+N_{A B} c_{A B}-\left(N_{A B}+1\right) c_{j}}{N_{j}+N_{A B}+1}, j=A, B \text { and } \\
q_{j 3}^{*}=\frac{D_{j}+N_{j} c_{j}-\left(N_{j}+1\right) c_{A B}}{N_{j}+N_{A B}+1}, j=A, B .
\end{gathered}
$$

Moreover, reduced profit functions equal

$$
\begin{gathered}
\Pi_{A}(\mathbf{N})=q_{A}^{*^{2}}-F_{A}, \\
\Pi_{B}(\mathbf{N})=q_{B}^{*^{2}}-F_{B}, \text { and } \\
\Pi(A B)=q_{A 3}^{*^{2}}+q_{B 3}^{*^{2}}-F_{A B}
\end{gathered}
$$

Just as in the main body of the paper, I am interested in comparing profits observed in different situations $\mathbf{N}$ and $\mathbf{M}$. My goal is to determine how the parameters affect the evolution of the game. Take the example of $\Pi_{A}(\mathbf{N})-\Pi_{B}(\mathbf{M})$,

$$
\begin{aligned}
\Pi_{A}(\mathbf{N})-\Pi_{B}(\mathbf{M})=q_{A}^{*^{2}}-F_{A}-q_{B}^{*^{2}}+F_{B}= \\
\quad(M(B)+M(A B)+1)^{2}\left(D_{A}+N(A B) c_{A B}-(N(A B)+1) c_{A}\right)^{2} \\
\quad(N(A)+N(A B)+1)^{2}\left(D_{B}+M(A B) c_{A B}-(M(A B)+1) c_{B}\right)^{2} \\
\quad(M(B)+M(A B)+1)^{2}(N(A)+N(A B)+1)^{2}\left(F_{B}-F_{A}\right)
\end{aligned}
$$

Interim Reports on work of the International Institute for Applied Systems Analysis receive only limited review. Views or opinions expressed herein do not necessarily represent those of the Instiute, its National Memeber Organizations, or other organizations supporting the work. 
Suppressing fixed costs as well this reduces to

$$
\begin{aligned}
& \Pi_{A}(\mathbf{N})-\Pi_{B}(\mathbf{M})=q_{A}^{*^{2}}-F_{A}-q_{B}^{*^{2}}+F_{B}= \\
& \quad(M(B)+M(A B)+1)^{2}\left(D_{A}+N(A B) c_{A B}-(N(A B)+1) c_{A}\right)^{2} \\
& \quad(N(A)+N(A B)+1)^{2}\left(D_{B}+M(A B) c_{A B}-(M(A B)+1) c_{B}\right)^{2}
\end{aligned}
$$

The problem with this expression is that I do not see any re-parametrization that would allow me to seperate the influence of the parameters on the one hand, and of the variables $\mathbf{N}$ on the other hand. This nuisance comes up as well when comparing $\Pi_{A B}$ to $\Pi_{A}$. As a consequence, one has to split the domain of, say, $D_{A}$ in intervals, then, for every such interval split up the domain of $D_{B}$, and then, for relative values of $c_{A}, c_{B}$, and $c_{A B}$ determine the evolution of play. This leads to hundreds of cases to be studied. One can, of course, readily determine the equilibria for the one-shot, complete information game; the absence of a convenient re-parametrization is only a problem when I explicitly have to calculate the evolution of the game.

Another problem that comes up is the following. In determining the optimal quantities $q_{j}^{*}$ and $q_{j 3}^{*}$ knowledge of marginal cost parameters $c$ of products produced with other technologies is required, possibly even of those production processes that were never used before. This is similar to the situation in Milgrom and Roberts' (1982) limit pricing model, where ex-ante the potential entrant and the incumbent just have a probability distribution over the possible marginal costs of the incumbent, but marginal costs of both entrant and incumbent become common knowledge once the entrant enters the market. Although this does not seem to pose a problem in their paper, it is difficult to reconcile with the thrust of the present paper where information gathering occupies centre stage.

\section{B The Equilibria of the One-Shot Games}

The one-shot games are defined by

$$
\Gamma=\{i, A(i), \Pi(i)\}_{i=1, \ldots, N}
$$

where the first element denotes the firms, $A(i)$ the action sets, and $\Pi(i)$ the profit functions. Remember that the GIG action sets are defined as

$$
A(i)=\{\{A\},\{B\},\{A, B\}\}
$$

irrespective of $i$. LIG action sets are defined as

$$
\begin{gathered}
A(i)=\{\{A\},\{A, B\}\} \text { if } \mathcal{P}(i)=A \\
A(i)=\{\{B\},\{A, B\}\} \text { if } \mathcal{P}(i)=B \\
A(i)=\{\{A\},\{B\},\{A, B\}\} \text { if } \mathcal{P}(i)=A B
\end{gathered}
$$

Proposition 1 In the game $\Gamma$ of complete information defined above, with $N(A)+N(B)+$ $N(A B)=N, i$ fixed, and with GIG-action sets the following holds:

- $(N(A), N(B), N-N(A)-N(B))$ is the unique equilibrium for $\alpha=(N(A)+N(A B), N(A)+$ $N(A B)+1), \beta \in(N(B)+N(A B), N(B)+N(A B)+1)$.

Interim Reports on work of the International Institute for Applied Systems Analysis receive only limited review. Views or opinions expressed herein do not necessarily represent those of the Instiute, its National Memeber Organizations, or other organizations supporting the work. 
- $(N(A), N(B), 0)$ is the unique equilibrium for $\alpha-\beta \in(N(A)-N(B)-1, N(A)-$ $N(B)+1), \alpha<1+N(A)$ and $\beta<1+N(B)$.

- $(N(A), 0, N(A B))$ is the unique equilibrium for $\alpha>N$ and $\beta \in(N(A B), N(A B)+1)$.

- $(0, N(B), N(A B))$ is the unique equilibrium for $\beta>N$ and $\alpha \in(N(A B), N(A B)+$ $1)$.

- $(N, 0,0)$ is the unique equilibrium for $\beta<1$ and $\alpha-\beta>N-1$.

- $(0, N, 0)$ is the unique equilibrium for $\alpha<1$ and $\alpha-\beta<-N+1$.

- $(0,0, N)$ is the unique equilibrium for $\alpha>N$ and $\beta>N$.

Proposition 2 In the game $\Gamma$ of complete information defined above, with $N(A)+N(B)+$ $N(A B)=N$, $i$ fixed, and with LIG-action sets the following holds:

- $(N(A), N(B), N(A B))$ is the unique equilibrium for $\alpha \in(N(A)+N(A B), N(A)+$ $N(A B)+1), \beta \in(N(B)+N(A B), N(B)+N(A B)+1)$

- $(N(A), N(B), 0)$ is an equilibrium for $\alpha<1+N(A)$ and $\beta<1+N(B)$

- $(N(A), 0, N(A B))$ is the unique equilibrium for $\alpha>N$ and $\beta \in(N(A B), N(A B)+1)$

- $(0, N(B), N(A B))$ is the unique equilibrium for $\beta>N$ and $\alpha \in(N(A B), N(A B)+1)$

- $(N, 0,0)$ is an equilibrium for $\beta<1$

- $(0, N, 0)$ is an equilibrium for $\alpha<1$

- $(0,0, N)$ is the unique equilibrium for $\alpha>N$ and $\beta>N$

The proofs of these propositions can easily be derived from equations (15).

\section{Welfare Analysis}

In this section I discuss the welfare characteristics of the selected equilibria in case of LIG. I limit attention to the equilibria that are reached when learning is parametric or non-parametric.

In the first case, in the region $\alpha \times \beta \in\left(1,1+N_{A}\right) \times\left(1,1+N_{B}\right)$ the surplus maximizing combinations of firms are reached: $\left(N_{A}, N_{B}+N_{A B}, 0\right)$ for $\alpha-\beta<N_{A}-N_{B}$, and $\left(N_{A}+\right.$ $\left.N_{A B}, N_{B}, 0\right)$ for $\alpha-\beta>N_{A}-N_{B}$.

In the subspace $\alpha \times \beta \in\left(1,1+N_{A}\right) \times(\leftarrow, 1)$ the surplus maximizing equilibrium $\left(N_{A}+N_{A B}, N_{B}, 0\right)$ is reached for $\alpha-\beta<N_{A}+N_{A B}$, while for $\alpha-\beta>N_{A}+N_{A B}$ the surplus maximizing equilibrium $(N, 0,0)$ is not reached, but instead the second best $\left(N_{A}+N_{A B}, N_{B}, 0\right)$ is.

For the parameter values $\alpha \times \beta \in(\leftarrow, 1) \times\left(1,1+N_{B}\right)$ the surplus maximizing equilibrium $\left(N_{A}+N_{A B}, N_{B}, 0\right)$ is reached for $\alpha-\beta>N_{A}-N_{B}$; the surplus maximizing equilibrium $\left(N_{A}, N_{B}+N_{A B}\right)$ is reached for $\alpha-\beta \in\left(-N_{B}-N_{A B}, N_{A}-N_{B}\right)$. The surplus maximizing equilibrium $(0, N, 0)$ is not reached for $\alpha-\beta<-N_{B}-N_{A B}$; instead $\left(N_{A}, N_{B}+N_{A B}\right)$ is reached once again.

Interim Reports on work of the International Institute for Applied Systems Analysis receive only limited review. Views or opinions expressed herein do not necessarily represent those of the Instiute, its National Memeber Organizations, or other organizations supporting the work. 
Finally, for $\alpha \times \beta \in(\leftarrow, 1) \times(\leftarrow, 1)$ the surplus maximizing equilibria $\left(N_{A}+N_{A B}, N_{B}, 0\right)$ and $\left(N_{A}, N_{B}+N_{A B}, 0\right)$ are reached for $\alpha-\beta \in\left(N_{A}-N_{B}, N_{A}+N_{A B}\right)$ and $\alpha-\beta \in$ $\left(-N_{B}-N_{A B}, N_{A}-N_{B}\right)$, respectively. In the remaining regions, $\alpha-\beta<-N_{B}-N_{A B}$ and $\alpha-\beta>N_{A}+N_{A B}$, the surplus maximizing equilibria, $(0, N, 0)$ and $(N, 0,0)$ are not reached; instead, the next-best equilibria $\left(N_{A}, N_{B}+N_{A B}, 0\right)$ and $\left(N_{A}+N_{A B}, N_{B}, 0\right)$ are reached.

The welfare characteristics of the equilibria selected when learning is non-parametric are as follows. For $\alpha<1$ and $\beta \in\left(N_{A B}+N_{B}, N_{A B}+N_{B}+1\right)$ the equilibrium $(0, N, 0)$ that is reached gives rise to the highest surplus from amoung the other possible equilibria, with the exception for the small region where $\alpha-\beta<-N_{B}-N_{A B}$. Here it is the second best.

The equilibrium $\left(N_{A}, N_{B}+N_{A B}, 0\right)$ that comes up for $\beta<N_{A B}+N_{B}$ and $\alpha-\beta<$ $N_{A}-N_{B}$ is the best for $\alpha-\beta \in\left(-N_{B}-N_{A B}, N_{A}-N_{B}\right)$ and second best for the rest of the region. Similarily for $\left(N_{A}+N_{A B}, N_{B}, 0\right)$ that comes up for $\beta<N_{A B}+N_{B}, \alpha<N_{A}+N_{B}$ and $\alpha-\beta>N_{A}-N_{B}$. It is the best for $\alpha-\beta \in\left(N_{A}-N_{B}, N_{A}+N_{A B},\right)$ and second best for the rest of the region. 


\section{References}

R. Amit and P. J. H. Schoemaker (1993), Strategic Assets and Organizational Rent, Strategic Management Journal, 14, pp.33-46.

S. P. Anderson, A. De Palma, And J.-F. Thisse (1990), Discrete Choice Theory of Product Differentiation.

M. Y. An And N. M. Kiefer (no year), Local Externalities and Societal Adoption of Technologies, mimeo.

M. Y. An And N. M. Kiefer (1993), Evolution and Equilibria Selection of Repeated Lattice Games, mimeo.

C. Y. Baldwin And Kim B. Clark (1994), Capital-Budgeting Systems and Capabilities Investments in U.S. Companies after the Second World War, Business History Review, 68, pp. 73-109.

J. BARney (1991), Firm Resources and Sustained Competitive Advantage, Journal of Management, 17, pp.99-120.

W. J. Baumol, J. C. Panzar, and R. D. Willig (1982), Contestable Markets and The Theory of Industry Structure. New York etc.: Harcourt Brace Jovanovic.

L. E. Blume (1993), The Statistical Mechanics of Strategic Interaction, Games and Economic Behavior, 5, pp. 387-424.

G. R. CArroll (1985), Concentration and Specialization: Dynamics of Niche Width in Populations of Organizations, American Journal of Sociology, 90, pp. 1262-1283.

A. J. DiBella, E. C. Nevis, And J. M. Gould (1996), Understanding Organizational Learning Capability, Journal of Management Studies, 33, pp.361-379.

G. ElLison (1993), Learning, Local Interaction, and Coordination, Econometrica, 61, pp. 1047-1071.

G. Ellison And D. Fudenberg (1993), Rules of Thumb for Social Learning, Journal of Political Economy, 101, pp. 612-643.

M.T. Hannan And J. Freeman (1977), The Population Ecology of Organizations, American Journal of Sociology, 82, pp. 929-964.

M. T. Hannan and J. Freeman (1989), Organizational Ecology. Cambridge, Mass.: Harvard University Press.

H. Th. Johnson and R. S. Kaplan (1987), Relevance Lost. The Rise and Fall of Management Accounting. Boston, Mass.: Harvard Business School.

B. Jovanovic (1993), The Diversification of Production, Brookings Papers on Economic Activity (Microeconomics), pp. 197-235.

M. Kandori, G. J. Mailath, R. Rob (1993), Learning, Mutation, and Long Run Equilibria in Games, Econometrica, 61, pp. 29-56.

E. M. Leifer (1985), Markets as Mechanisms: Using a Role Structure, Social Forces, 64, pp. $442-472$.

E. M. Leifer And H. C. White (1987), A structural Approach to Markets, pp. 85-108 in Intercorporate Relations: The Structural Analysis of Business, edited by Mark S. Mizruchi and Michael Schwartz. Cambridge etc.: CUP.

Interim Reports on work of the International Institute for Applied Systems Analysis receive only limited review. Views or opinions expressed herein do not necessarily represent those of the Instiute, its National Memeber Organizations, or other organizations supporting the work. 
J T. Mahoney and J. Rajendran Pandian (1992), The Resource-Based View within the Conversation of Strategic Management, Strategic Management Journal, 13, pp.363-380.

P. Milgrom and J. Roberts (1982), Limit Pricing and Entry under Incomplete Information: An Equilibrium Analysis, Econometrica, 50, pp. 443-459.

S. S. Miller (1963), The Management Problems of Diversification. A Pilot Study of the Corporatoin Diversifying from an Established Base. New York: John Wiley, Inc.

K. Okuguchi And F. Szidarovszky (1990), The Theory of Oligopoly with Multi-Product Firms. Lecture Notes in Economics and Mathematical Systems 342. Berlin etc: Springer Verlag.

E. Penrose (1959), The Theory of the Growth of the Firm. Oxford etc.: Oxford University Press.

V. Ramanujam and P. Varadarajan (1989), Research on Corporate Diversification: A Synthesis, Strategic Management Journal, 10, pp.523-551.

R. P. Rumelt, D. E. Schendel, And D. J. Teece (eds) (1994), Fundamental Issues in Strategy: A Research Agenda. Boston, Mass.: Harvard Business School Press.

A. Shaked And J. Sutton (1990), Multiproduct Firms and Market Structure, RAND Journal of Economics, 21, pp. 45-62.

B. VisSER (1996), Harrison White on the Reproduction of Markets. mimeo, IIASA, Laxenburg, Austria.

B. Wernerfelt (1984), A Resource-base View of the Firm, Strategic Management Journal, 5, pp.171-180.

H. C. White (1981a), Production Markets as Induced Role Structures, pp. 1-57 in Sociological Methodology 1981, edited by S.L. Leinhardt. San Francisco: JosseyBass.

H. C. White (1981b), Where do Markets come from? , American Journal of Sociology, 87, pp.517-547.

H. C. White (1988), Varieties of Markets, pp.226-260 in Social Structures: A Network Approach, edited by Barry Wellman and S.D. Berkowitz. Cambridge etc.: CUP.

O. E. Williamson (1975), Market and Hierarchies: Analysis and Antitrust Implications. New York: The Free Press.

A. Wolinsky (1986), The Nature of Competition and The Scope of Firms, The Journal of Industrial Economics, 34, pp. 247-259.

Interim Reports on work of the International Institute for Applied Systems Analysis receive only limited review. Views or opinions expressed herein do not necessarily represent those of the Instiute, its National Memeber Organizations, or other organizations supporting the work. 


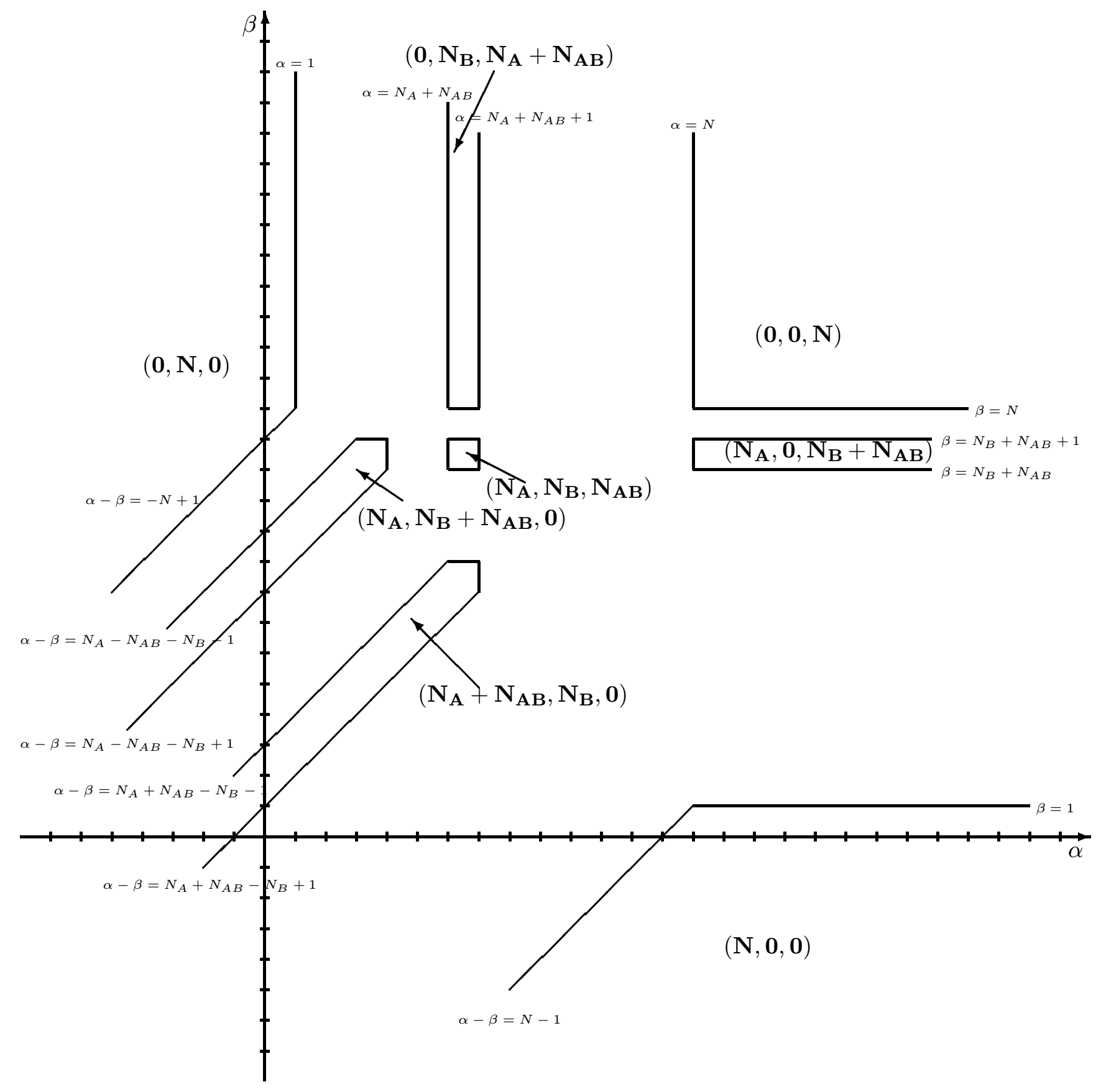

Figure 1: The relevant equilibria of the one-shot, complete information game with GIG action sets. 


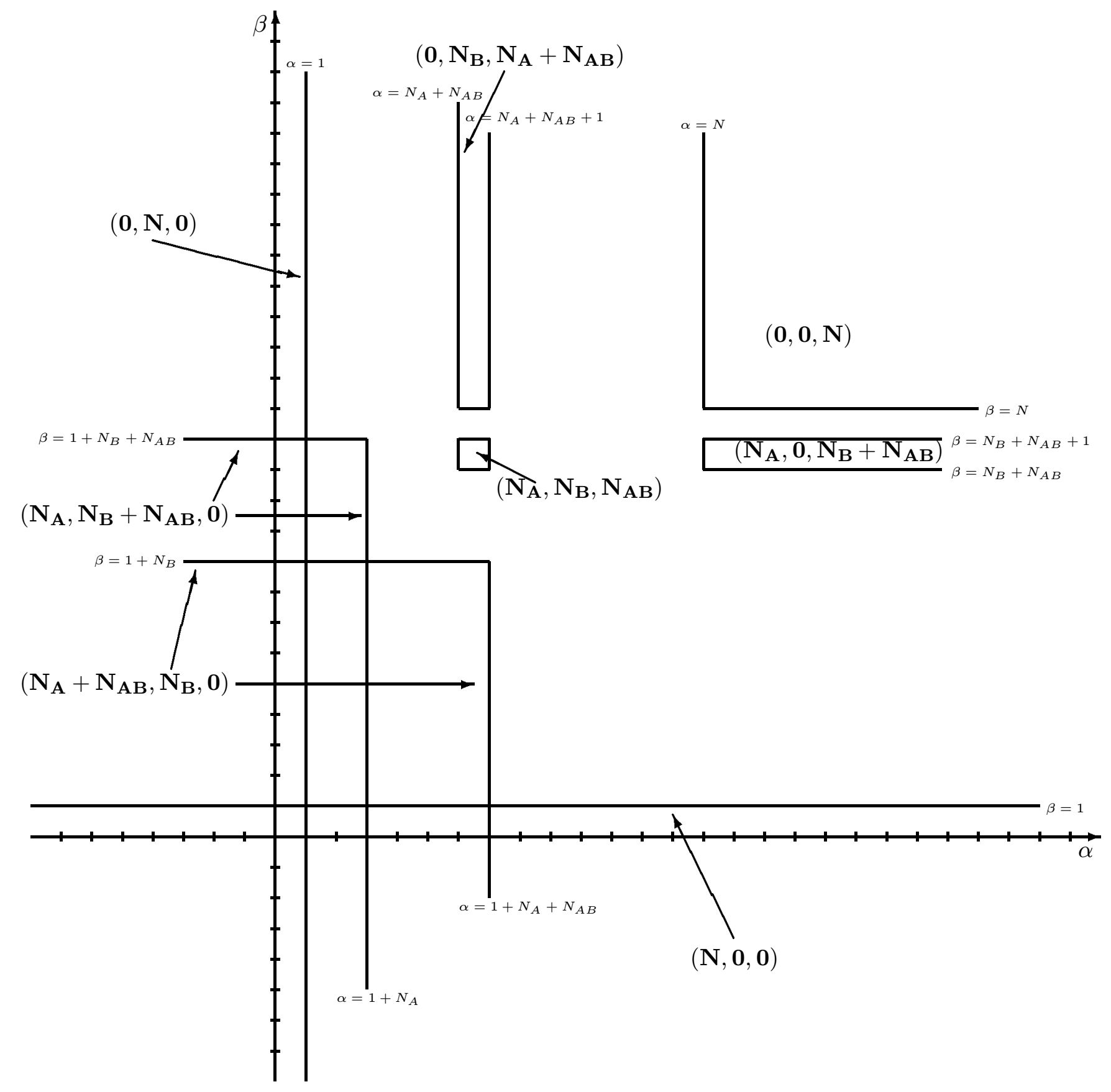

Figure 2: The relevant equilibria of the one-shot, complete information game with LIG action sets. 


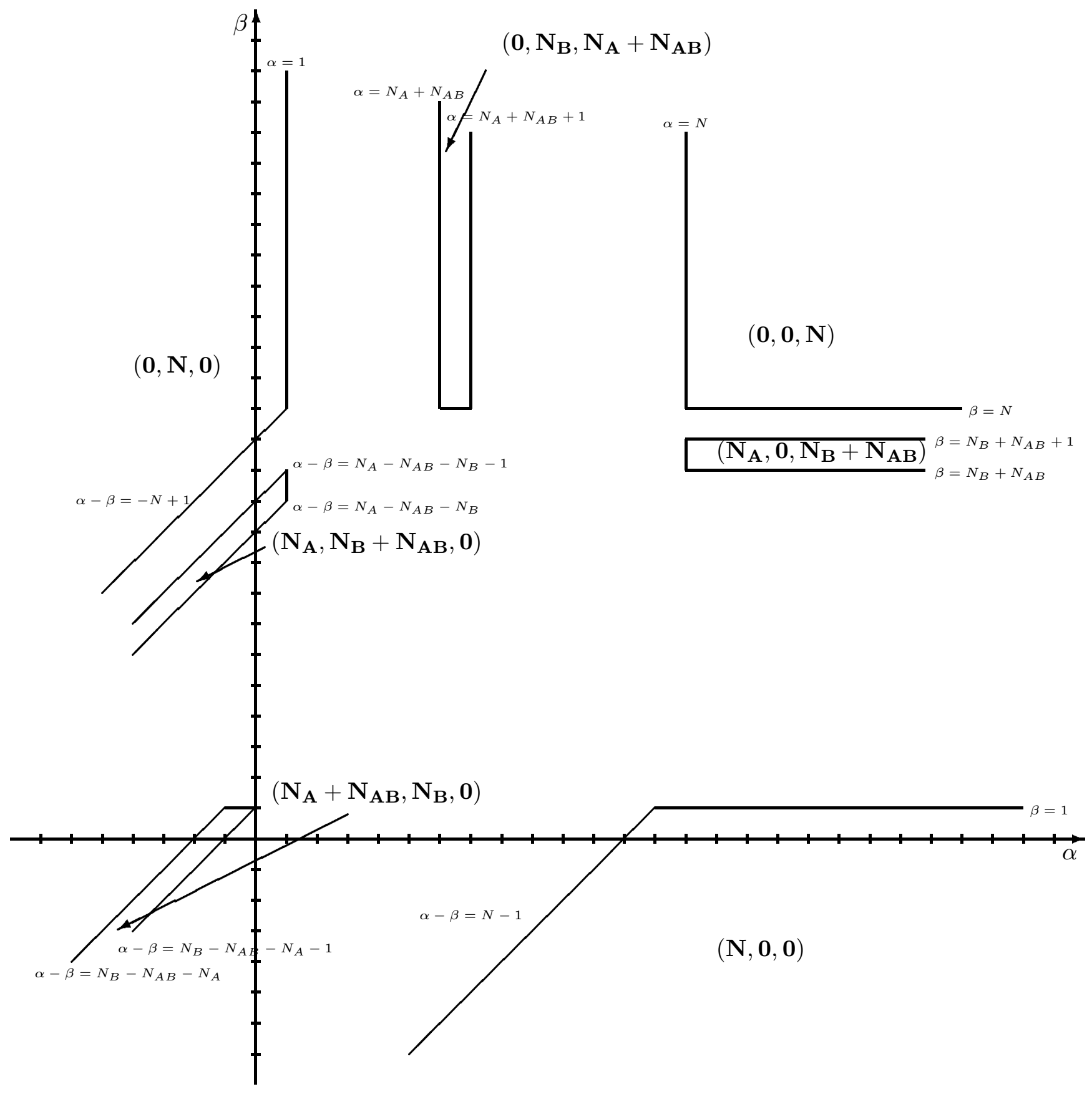

Figure 3: The equilibria in case of Global Information Gathering and Parametric Learning. 


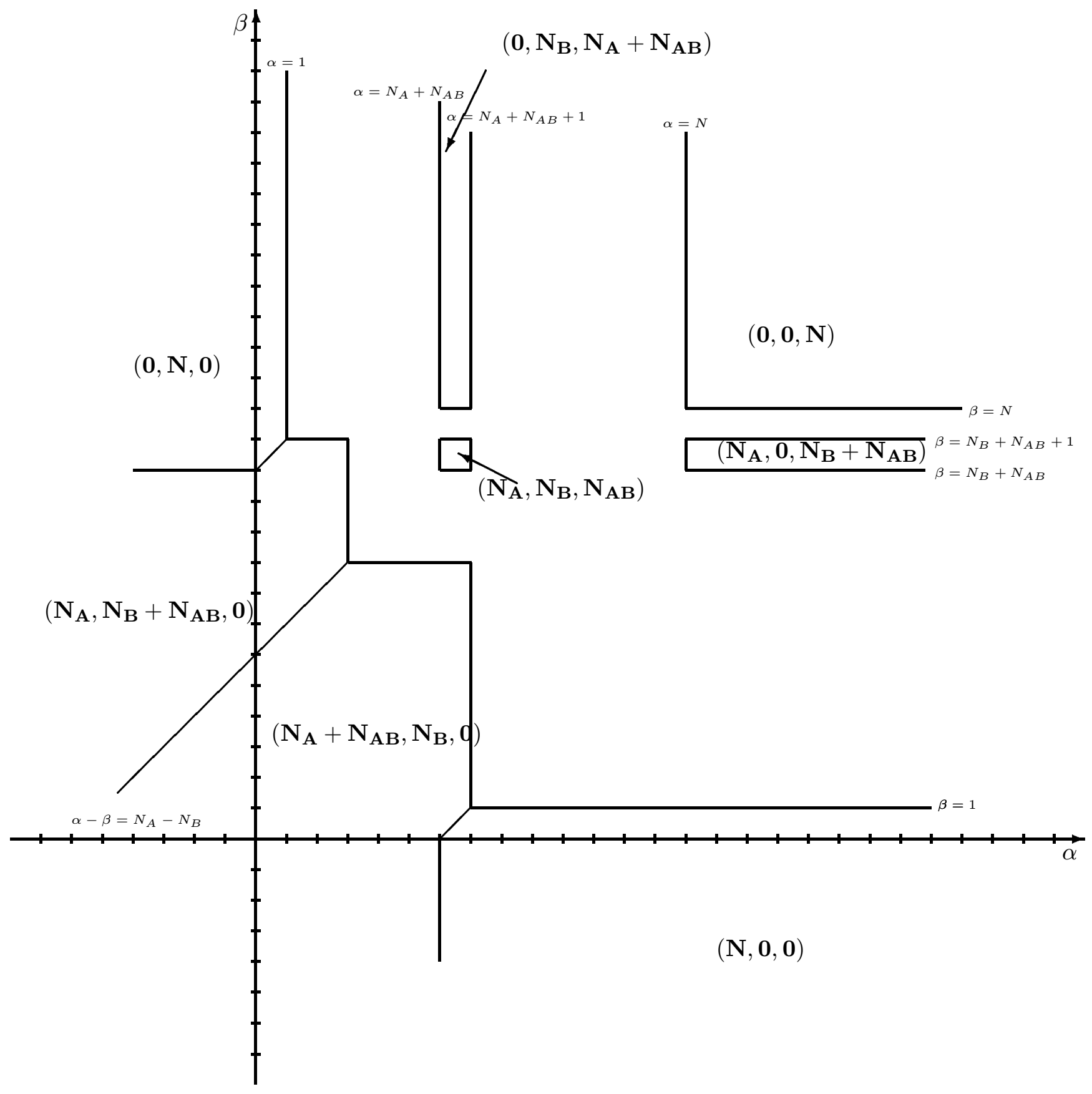

Figure 4: The equilibria in case of Local Information Gathering and Parametric Learning. 


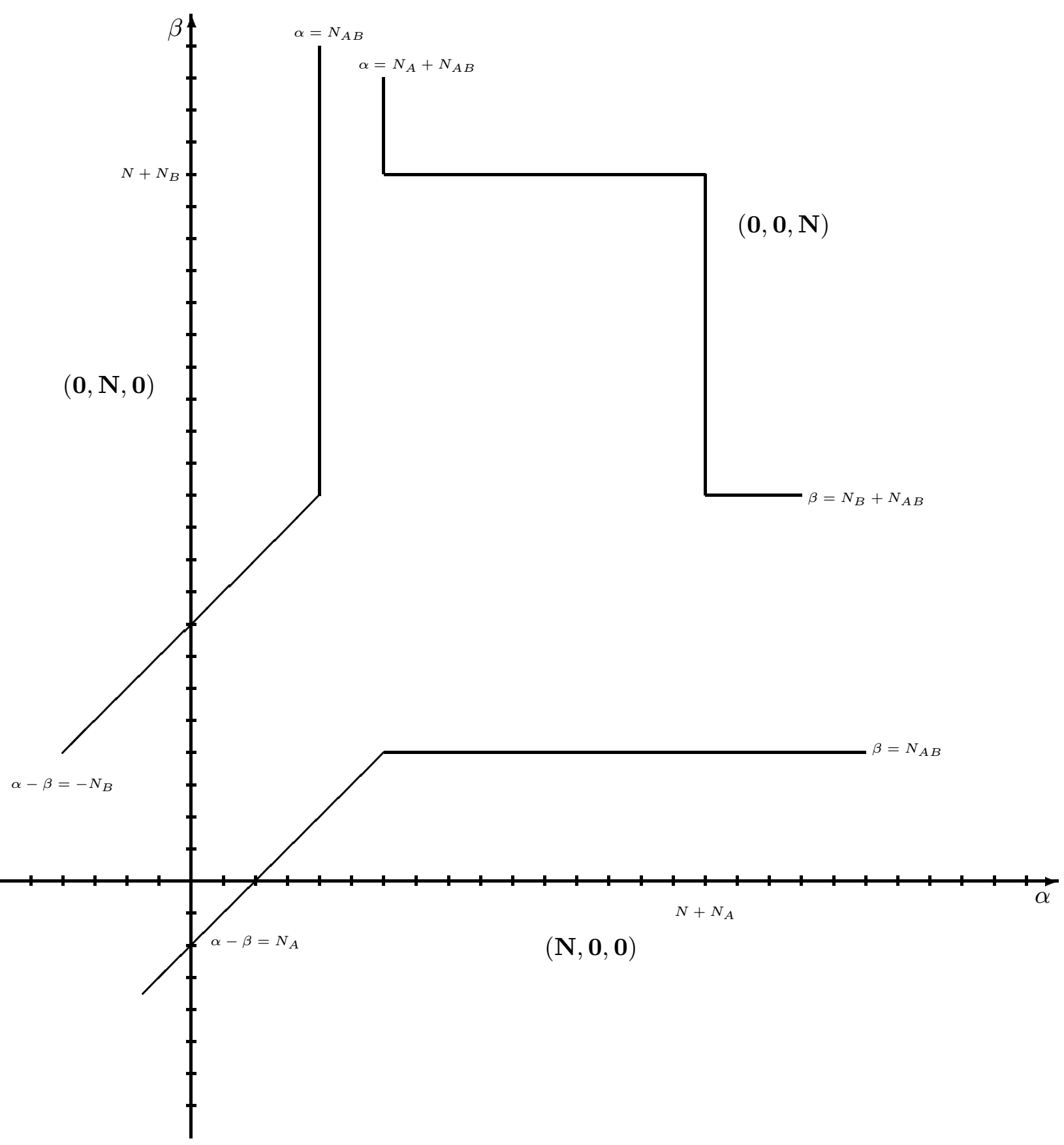

Figure 5: The equilibria in case of Global Information Gathering with Non-Parametric Learning. 


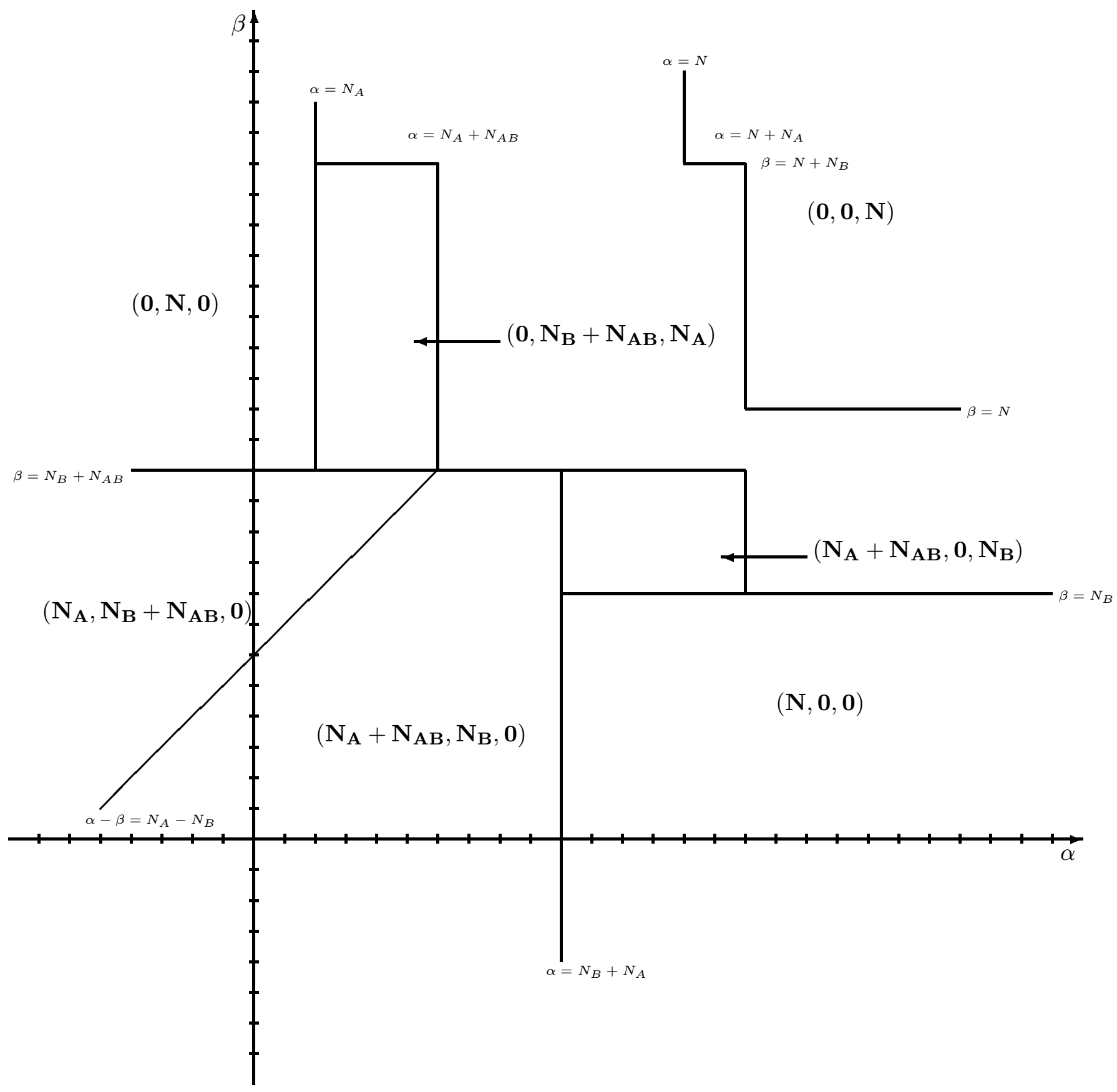

Figure 6: The equilibria in case of Local Information Gathering, with Non-Parametric Learning. 


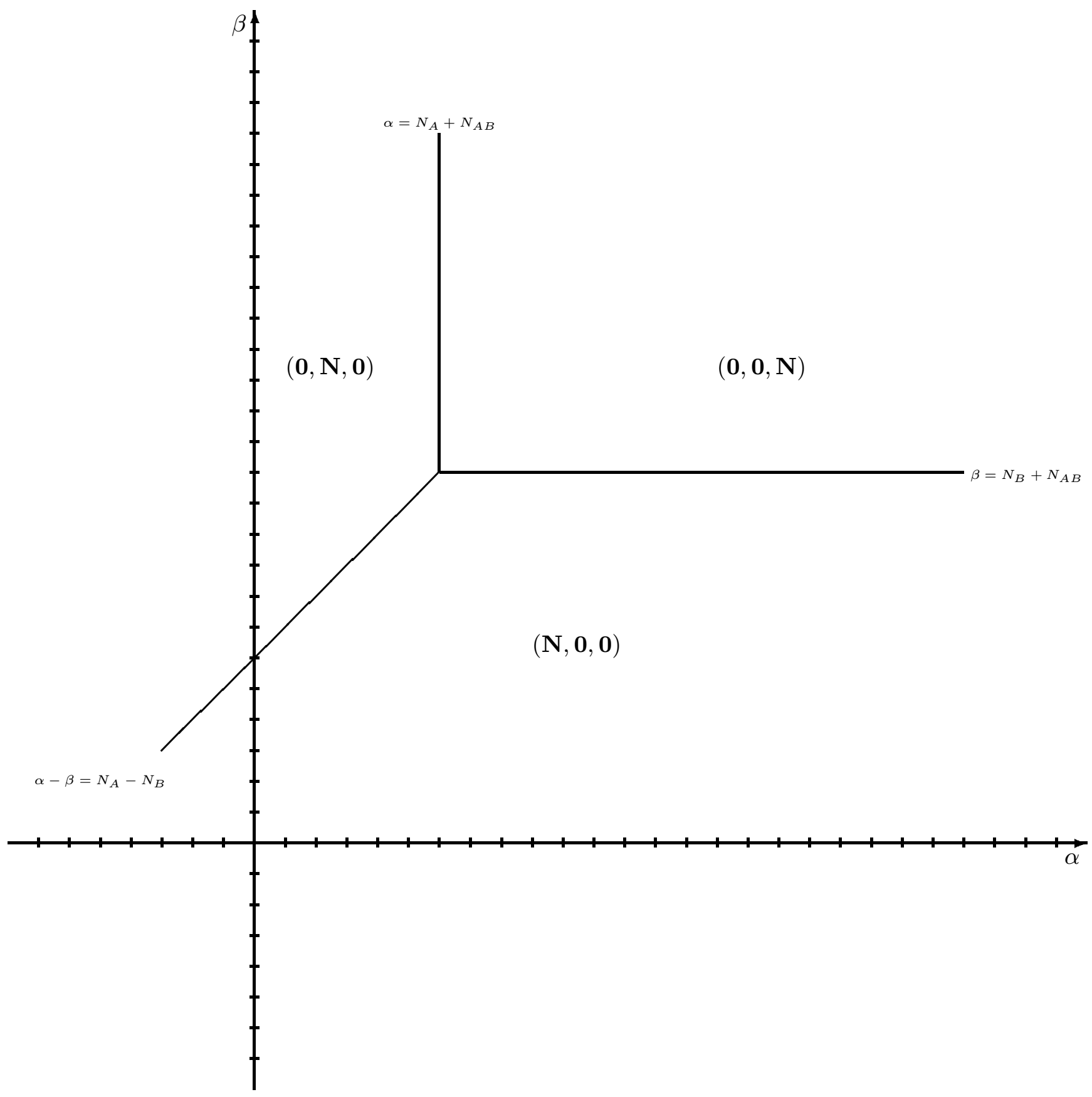

Figure 7: The equilibria when firms have only information on current product set, and when information gathering is global. 


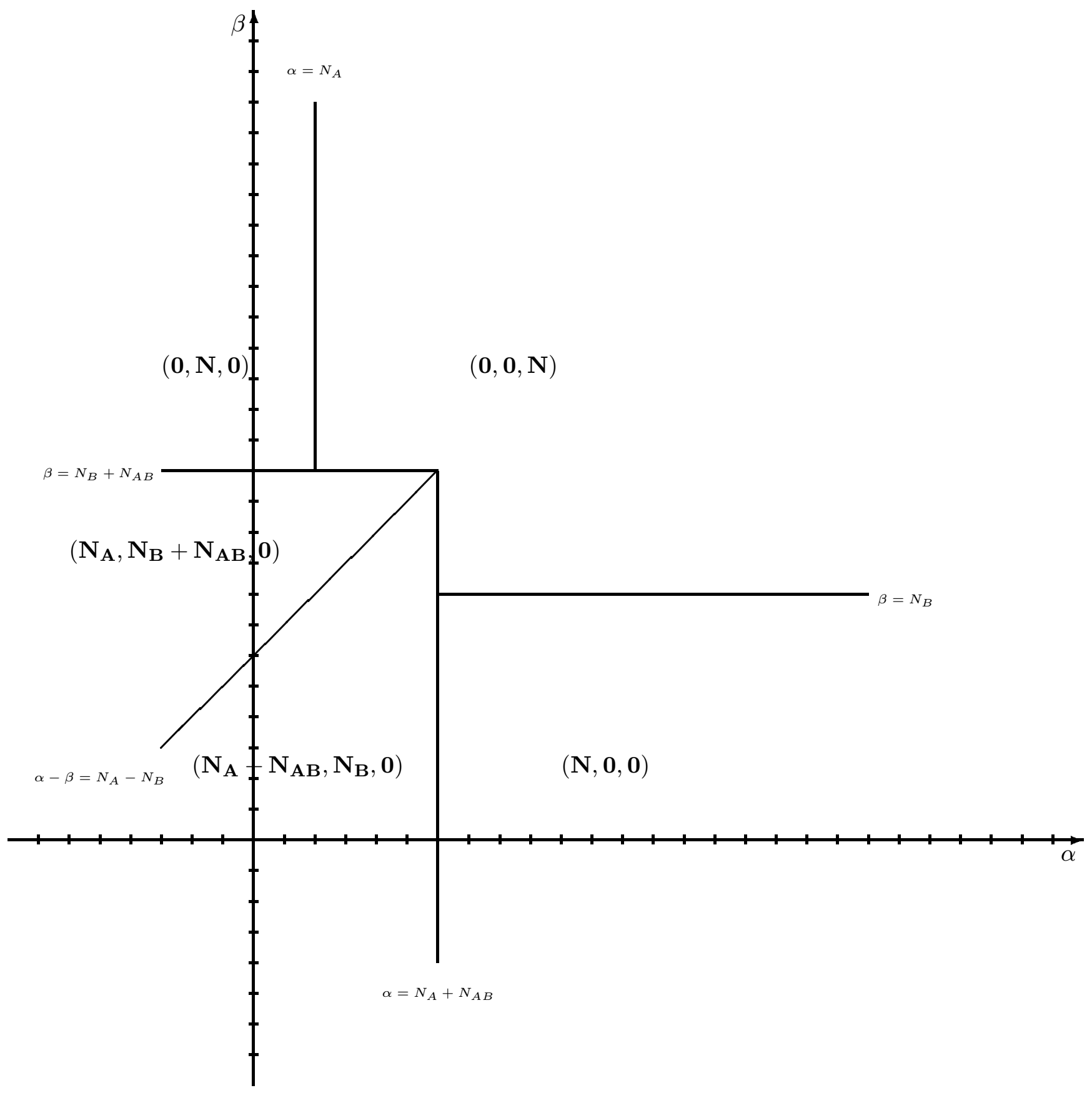

Figure 8: The equilibria when firms have only information on current product set, and when information gathering is local. 


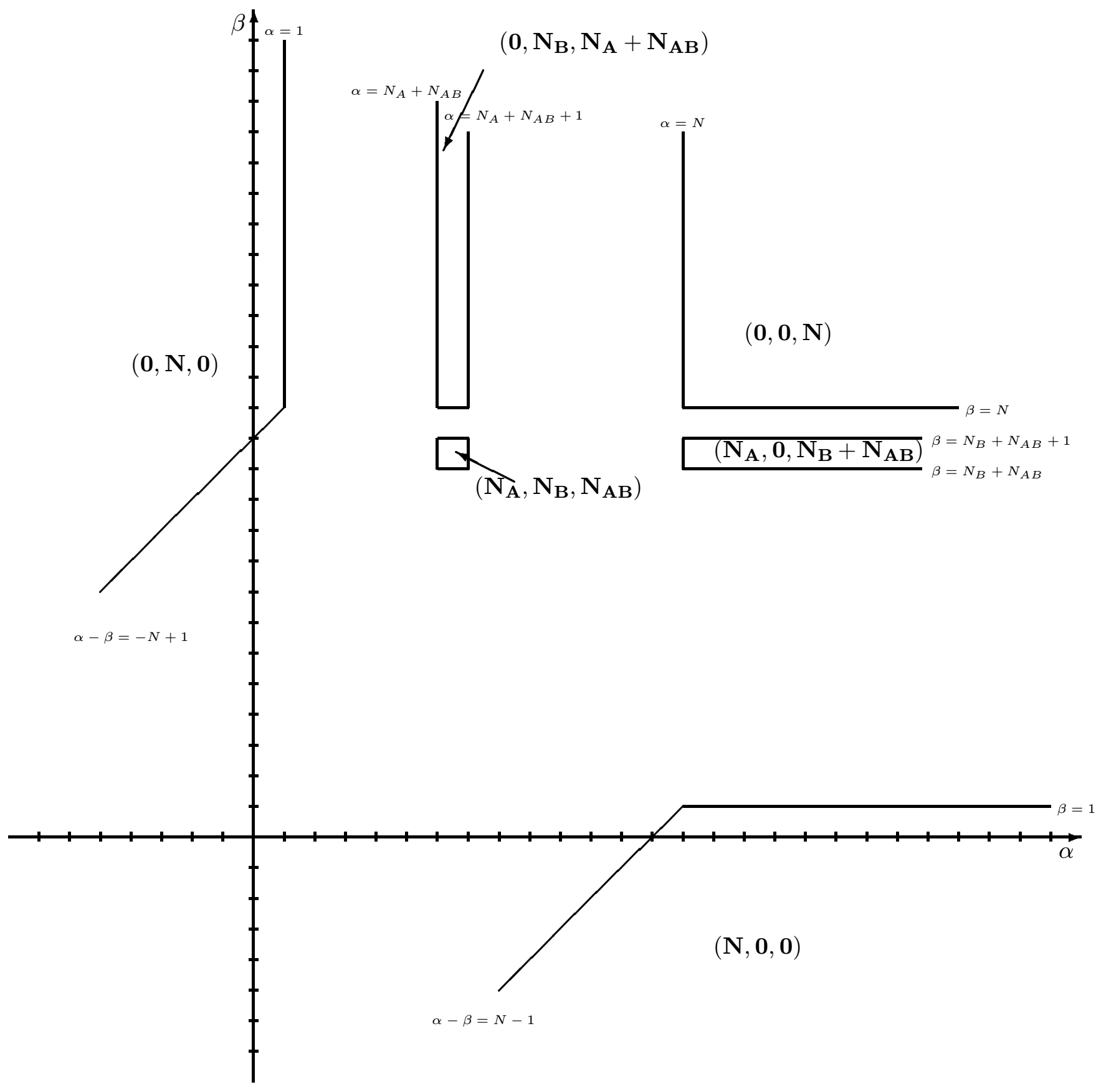

Figure 9: The equilibria when all parameters are known from the outset, and when successive product sets are not required to overlap. 


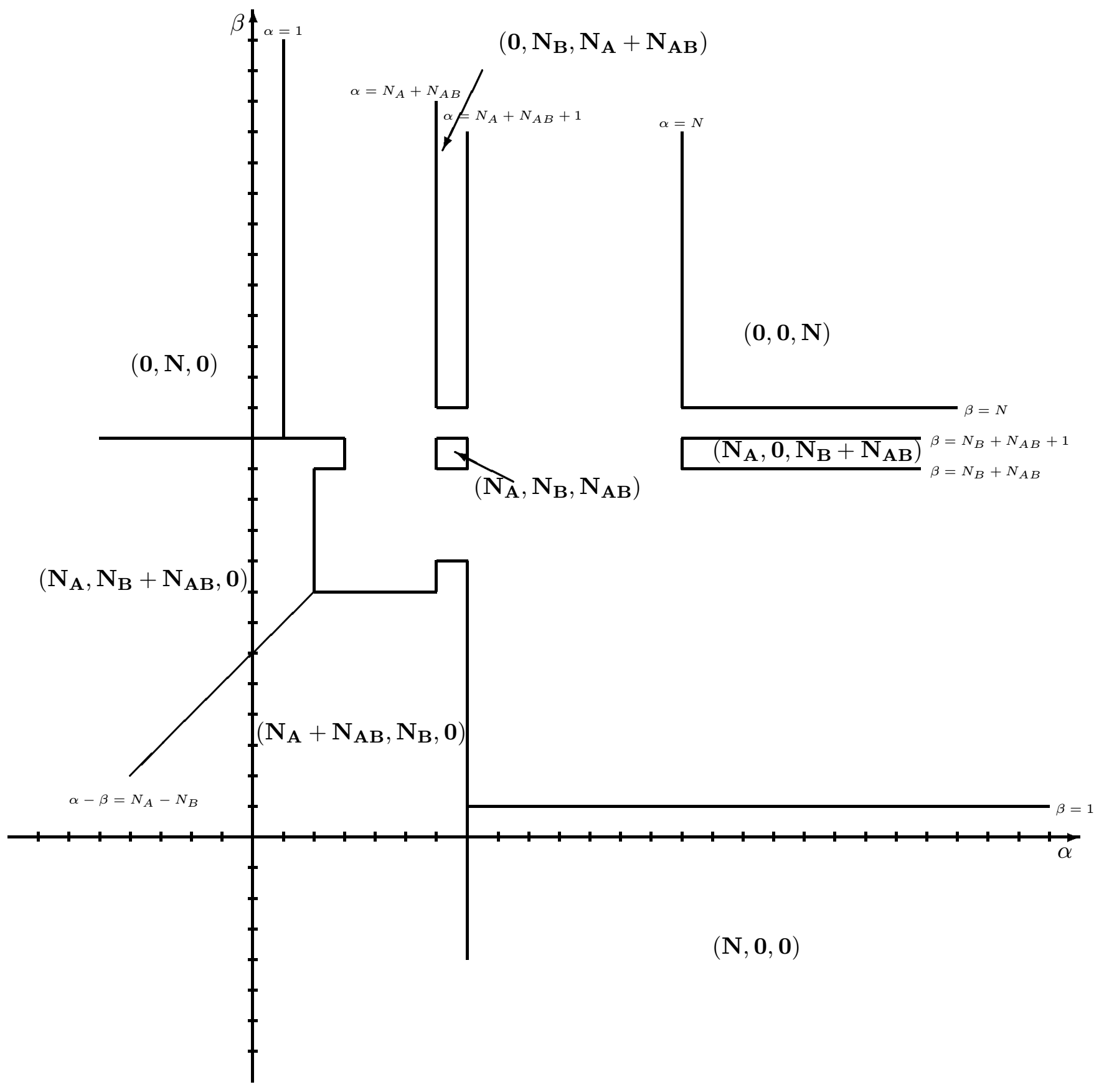

Figure 10: The equilibria when all parameters are known from the outset, and when successive product sets are required to overlap. 